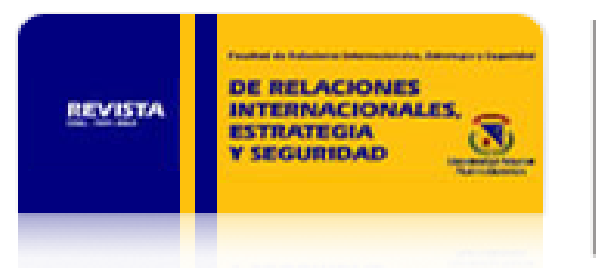

Revista de Relaciones Internacionales, Estrategia y Seguridad

ISSN: 1909-3063

cinuv.relinternal@unimilitar.edu.co

Universidad Militar Nueva Granada

Colombia

Ghotme, Rafat

Relaciones Internacionales de las Guerras Civiles, Colombia, 1885-1903

Revista de Relaciones Internacionales, Estrategia y Seguridad, vol. 2, núm. 1, enero-junio, 2007, pp. 13-50

Universidad Militar Nueva Granada

Bogotá, Colombia

Disponible en: http://www.redalyc.org/articulo.oa?id=92720102

- Cómo citar el artículo

- Número completo

- Más información del artículo

- Página de la revista en redalyc.org

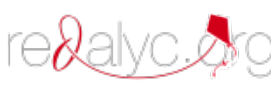

Sistema de Información Científica

Red de Revistas Científicas de América Latina, el Caribe, España y Portugal Proyecto académico sin fines de lucro, desarrollado bajo la iniciativa de acceso abierto 
rev.relac.int.estrateg.segur.2(1):13-50,2007

\title{
RELACIONES INTERNACIONALES DE LAS GUERRAS CIVILES, COLOMBIA, 1885-1903'
}

\author{
Por Rafat Ghotme**
}

\section{RESUMEN}

Esta investigación se propone hacer un estudio de las relaciones internacionales de (o producidas por) las guerras civiles. Se plantea el hecho de que las Relaciones Internacionales de Colombia tiene una organización especial y dedicada exclusivamente al tratamiento de la Guerra Civil bajo la perspectiva histórico-internacional: las relaciones con sus vecinos, las formas como se incorporan los tipos de Derecho Internacional, Derecho Diplomático y Consular, los Tratados de extradición, comercio, unión, cooperación, son los mecanismos más utilizados por el Estado colombiano para darle tratamiento o una solución negociada a la Guerra Civil.

\footnotetext{
* Este artículo es un extracto de la Investigación, que lleva el mismo título, presentada al Centro de Investigaciones de la Facultad de Relaciones Internacionales, Estrategia y Seguridad, en marzo de 2007. Si se omiten algunas cosas, sugiero al lector remitirse al texto completo de la Investigación.

** Docente del Programa de Relaciones Internacionales y Estudios Políticos, UMNG.
} 
Palabras Clave: Relaciones Internacionales, Historia, Guerra Civil, Política Exterior, Venezuela, Ecuador, Estados Unidos, Paradiplomacia

\section{ABSTRACT}

This investigation intends to make a study of the international relationships of (or taken place for) the civil wars. It thinks that the International Relationships of Colombia have a special organization and dedicated to Civilian War treatment exclusively the historical-international perspective: the relationships with their neighbors, the forms like they incorporate the types of International Right, Diplomatic and Consular Right, the extradition Treaties, trade, union, cooperation, they are the mechanisms more used by the Colombian

Key Words: Interrnational Relations, History, Civil War, Foreign Politics, Venezuela, Ecuador, United States, Paradiplomacia.

\section{PRELIMINAR}

I. Este es un trabajo referente a la Historia de las Relaciones Internacionales. Sirve de advertencia preliminar para que no sea juzgado de lo que no pretende ser, esto es, de una sociología histórica de las Relaciones Internacionales, o de un estudio de Relaciones Internacionales estrictamente. En tal sentido, si bien reconozco la existencia de los más recientes trabajos de Relaciones Internacionales aplicadas a las guerras civiles, en el marco aquí propuesto sobresalen los elementos aportados por la disciplina de la Historia de las Relaciones Internacionales. Una Historia de las Relaciones Internacionales, tal y como la refirió Pierre Renouvin, más bien intenta dilucidar las fuerzas profundas que acontecen en el telón de fondo de una política exterior, sus determinantes y las formas como se interrelacionan para acometer una política específica: las fuerzas profundas en el sentido de los movimientos ideológicos, culturales, económicos y migratorios. Aunque es difícil responderlo, vale la pena preguntarse ¿qué determina a qué?, ¿la política exterior al sistema internacional, o a la inversa? Existen razones para creer que las Relaciones Internacionales son un cúmulo de acontecimientos derivados del accionar estatal, pero esta presunción, excesivamente vaga, debiera incorporar las fuerzas profundas -globales- que determinan la política exterior de un Estado; del mismo modo, seguimos creyendo que tales «fuerzas» no son fuerzas sin el carácter subjetivo que le imprimen los hombres -y pocas mujeres- de estado, quienes actúan motivados por intereses particulares, intereses nacionales, $y$, por supuesto, por una maquinaria racional muchas veces pasional- de decisiones proyectadas al sistema internacional. 
II. La Historia de las Relaciones Internacionales de Colombia durante el siglo XIX ha sido tradicionalmente esbozada bajo dos tópicos: el primero es la cuestión referente a la soberanía territorial en Centroamérica, el Caribe y los países vecinos, que incluye el periplo agobiante que encerró la construcción de un canal interoceánico en Panamá; y el segundo, que hace referencia a las relaciones de dominación y hegemonía -imperialismo- suscitadas entre Gran Bretaña y Estados Unidos y la subsecuente política del equilibrio del poder trial que tuvo un punto de encuentro durante los años 1840-1850, y desembocó en el paulatino desplazamiento de Gran Bretaña y la consolidación definitiva de Estados Unidos como potencia influyente en Colombia y el Caribe desde finales del siglo XIX. En los dos tópicos, el estado colombiano se ha caracterizado por tener una política exterior con una orientación "legalista», capaz de mantener, en lo posible, la defensa de la soberanía nacional, la cooperación con los demás países, la solidaridad y una egregia pulcritud, propia del espíritu y el genio colombianos, para dirigir su diplomacia.

En este trabajo, sin embargo, tratará de desarrollarse una tercera vía que dirija la atención de la Historia de las Relaciones Internacionales de Colombia, asumida bajo la óptica de las dos presunciones anteriores; también reconocerá el carácter legalista-civilista que sustentaron los parámetros de la política exterior durante el siglo XIX, más allá de la existencia de los casos excepcionales de diplomacia secreta o guerrerista de algunos caudillos colombianos. Esta tercera vía está enfocada en los aspectos críticos de las relaciones internacionales que se suscitaron o fueron producto de las Guerras Civiles durante el periodo 1885-1903, esto es, que abarca el periodo de la Regeneración y las tres guerras intestinas $(1885,1895$ y 1899) que tuvo que soportar el Estado para legitimar su proyecto político de Nación.

Tal enfoque debe precisar varias cosas: si bien un estudio de las relaciones internacionales de (y no durante) las guerras civiles se propone analizar cuáles son los hechos que son afectados por fuerzas internacionales, en el caso de las Relaciones Internacionales durante la Guerra Civil, por el contrario, se admite una perspectiva más amplia que incluso va más allá de los acontecimientos específicos de tal confrontación. Más aún, el estudio de las relaciones internacionales durante las guerras civiles contribuye particularmente a entender por qué o cuáles son las razones por las que el Estado actuó de una manera particular y en algunos casos con la tirantez habitual producida por los efectos de la rebelión, como son los casos del cambio de régimen, su reconocimiento, las acreditaciones de funcionarios diplomáticos y consulares, etc.; del mismo modo, también es útil para entender las desviaciones o el curso de algún suceso de la política exterior de los Estados destinatarios o receptores en los asuntos relevantes entre ambos actores, tal como sería el caso de las negociaciones en torno al Canal de Panamá, los tratados comerciales y las reuniones periódicas de carácter latino o panamericano. 


\section{INTRODUCCIÓN}

En el Informe que el Ministro de Relaciones Exteriores, don Antonio Gómez Restrepo, presentó al Congreso en 1898, adujo que las relaciones de Colombia con sus países vecinos debería basarse "en sentimientos de lealtad, que no juzga letra muerta los deberes internacionales y que considera como altamente perniciosa la tendencia que en los últimos tiempos y en varios países americanos han mostrado las guerras civiles, á buscar apoyo en movimientos de carácter internacional, manchándose así con un doble crimen" (Anales, IV, 1914:741). Todos los informes de los Ministros de Relaciones Exteriores durante las guerras civiles que comprende este estudio $(1885,1895,1899)$ hacen esta misma denuncia directa o indirectamente (Anales, IV, 1914:341-342; Diario Oficial, 1895, 1900, 1901). Ahora bien, ¿a qué se refieren los Ministros con eso de que en los últimos tiempos y en varios países americanos las guerras civiles han buscado apoyo en movimientos de carácter internacional? Desde el punto de vista de las Relaciones Internacionales, una guerra civil o conflicto armado interno es pertinente para el analista internacional sólo en la medida en que este conflicto esté afectado por hechos o fenómenos internacionales, como, por ejemplo, trascender sus fronteras nacionales o la intervención extranjera. En esta investigación vamos a seguir la propuesta que hiciera Karl Deutsch (1968:25, 110):

\footnotetext{
“¿Y cuáles son los efectos de tales procesos de revolución, contrarrevolución y posible estabilización de un orden político o social viejo o nuevo, sobre el curso de la política internacional? ¿Cómo, en síntesis, pueden afectar las revoluciones internas a los asuntos internacionales, y cómo pueden afectar las influencias extranjeras y los eventos internacionales a la estabilidad o el derrocamiento revolucionario de los regímenes internos y los sistemas políticos de determinados países?".
}

En los textos de Historia Diplomática consultados existe una tendencia por hacer una explicación sustancial, más bien aligerada, que demuestra una vez más el carácter civilistalegalista de sus autores. El afluente internacional de las guerras civiles se limita a interpretarse como una mala consecuencia de diversos incidentes relacionados con el orden público, los derechos y deberes de los extranjeros -en muchos casos considerados como extranjeros perniciosos o de conducta viciada, y las indemnizaciones a que éstos puedan tener derecho; en el peor de los casos, el afluente recae sobre habitantes y funcionarios de la administración local fronteriza que son movidos por el fanatismo religioso (en el caso de los conservadores) o su desapego a la Patria y las leyes (en el caso de los liberales). Además, si seguimos a Rivas (1961:474), cuando dice que "el poco interés de parte de los Estados para ayudar a prevenir a reprimir los atentados contra los extranjeros", demuestra una vez más el estado positivizado en que se encuentra el estudio de las relaciones internacionales de las guerras civiles.

De cualquier modo, deben anotarse varias precisiones. En primer lugar, contamos con algunos factores endógenos. En 1885 todavía podían notarse los remanentes de la última constitución 
federal de Colombia, en donde a pesar de que el manejo de las relaciones exteriores del país recaía sobre el gobierno nacional, aún los Estados Soberanos (en especial los fronterizos) tendían a asumir individualmente la mayoría de prerrogativas políticas y económicas abrogadas por la Constitución de 1863. Las disposiciones de la ley sobre orden público vigente durante el periodo anterior a 1885-1903, que obligaba al gobierno nacional a observar la más estricta neutralidad en las revoluciones que tuvieran lugar en los Estados de la federación, si tendía a hacer efectiva la soberanía de éstos, en cambio, resultó en una fuente inagotable de conflictos supeditada a defender la garantía constitucional de la soberanía individual de cada uno de éstos, en perjuicio del gobierno nacional.

Además, desde el punto de vista del ordenamiento territorial federalizado, los Estados Soberanos habían conformado conglomerados de territorios dislocados geográfica y culturalmente con el propósito de optimizar o centralizar la administración tributaria y la defensa del orden público estatal. Sin embargo, en la práctica, a los gobiernos centrales de los Estados Soberanos los desvelaba el hecho de contar con algunas Provincias rebeldes con cierto grado de maniobrabilidad autónoma, especialmente cuando se trataba de algún ataque a los dogmas y la institución de la Iglesia Católica. El ejemplo más claro de esto lo puede suministrar el Estado Soberano del Cauca, con zonas fronterizas inundadas de pueblos con gentes y funcionarios locales que seguían preferiblemente a algún sacerdote o caudillo conservador antes que a las propias autoridades estatales o nacionales. Del lado opuesto, podemos contar con el ejemplo clásico del Estado Soberano de Santander, liberal y secular, casi siempre en pie de lucha para defender su bandera. Y ese mismo Estado proporcionó, a través de su frontera con el Táchira, las bases para adelantar o enganchar rebeldes liberales de ambos lados de la frontera, sea para atacar al gobierno conservador colombiano sea para soportar el gobierno liberal venezolano.

Las guerras civiles durante el periodo 1885-1903 también obligaron a Colombia a proponer la elaboración de cambios drásticos en las doctrinas de política exterior referente a las funciones diplomáticas y consulares. Dice Rivas (1961:518-519): "La guerra civil de 1885, que tan fundamental cambio efectuó en las instituciones políticas del país, al sustituir un federalismo exagerado con un rígido centralismo, determinó igualmente modificaciones en la orientación y métodos de la política internacional de Colombia". Especialmente, esto se reflejó en la controversia sobre el derecho diplomático y consular que rondó todos los círculos sociales y políticos de Bogotá en 1885, como veremos más adelante. Entre otras cosas, el estudio de las relaciones internacionales de Colombia que se encarga de establecer el balance en el equilibrio del poder entre Gran Bretaña y Estados Unidos, encasillado tradicionalmente en los estudios en torno al imperialismo y al colonialismo, ha sido reticente al desconocer que la Constitución del 86, como elemento endógeno, juega un papel relevante en la configuración de la política exterior colombiana. De este modo, se pudo establecer, por ejemplo, que la costumbre 
política colombiana que tiende por desentrañar su espíritu legalista-civilista, obedecía también a su proyección internacional en el marco de una Comunidad de Naciones confederadas en la América Latina, capaz de solventar las crisis o amenazas de reconquista europea o las propias crisis internas, pero adecuadas a los preceptos del Derecho; por el contrario, también se pudo establecer que el caudillismo que se produjo en el resto del continente durante el siglo XIX no obedecía exclusivamente a factores endógenos o de la cultura política interna de esos países, sino que también fue motivado por el impulso asolador que traía consigo el embate de las reconquistas europeas. Por lo demás, Colombia siempre se manifestó predispuesta a los caudillismos y militarismos de la América Latina y se mantuvo firme en su fe por la diplomacia y el espíritu latino de la civilización; pero asumir tal posición también la enfrascó en una serie de predisposiciones diplomáticas de carácter secreto, clandestino, puesto que para mantener su legitimidad en el concierto internacional se vio obligada a reforzar lazos de unión -secretoscon regímenes amigos o aliados. Prueba de ello fue el apoyo secreto a Chile en su guerra con el Perú por los territorios de Tacna y Arica, y, en otra ocasión, la alianza secreta con Perú para delimitar su territorio fronterizo en desvarío de Ecuador (ver más adelante cómo Ecuador busca una alianza con los rebeldes liberales de Venezuela y Colombia para reformar la Gran Colombia, en respuesta a la posición colombo-peruana). En pocas palabras: si Colombia alentó una posición civilista-legalista de sus relaciones internacionales, existieron situaciones críticas que en el fondo sólo pudieron encontrar una solución práctica a través de lo que en este estudio denominaremos paradiplomacia o diplomacia secreta.

Existen también otros factores exógenos. En un estudio elaborado en Francia en 1903, por M. Antoine Rougier (extracto en D.M.P., 1904:218-219) titulado Les Guerres Civiles et le Droit des Gens, asumió el reto de incorporar un pasaje de la guerra civil colombiana de 1899 para explicar los cambios profundos por los que estaba atravesando el mundo occidental desde finales del siglo XIX. Dice: "Los lazos intelectuales, económicos, políticos y sociales se desarrollan entre las naciones rápida y firmemente", y por tal razón el principio de la nacionalidad cada vez más suele ser vulnerado. Como la guerra de 1899 fue una guerra entre partidos del lado venezolano y colombiano, y no entre naciones, dice Rougier, "el jurisconsulto no puede fácilmente darles nombre científico". Continua diciendo que la guerra de 1899 no era internacional, "puesto que no se efectuaba entre dos estados; tampoco era civil, porque no tenía lugar entre un Estado, por una parte, y un grupo insurrecto, de la otra". Era, en síntesis, un "tipo de guerra enteramente nuevo", motivada por el espíritu internacional de los flujos sociales, económicos e intelectuales de la época. El hecho es que para este autor francés la Guerra de los Mil Días adquirió una importancia y consecuencias poco vistas antes, que, como diría Urrutia (1928:269), "el derecho es estricto en la guerra internacional y en materia de Derecho Internacional, pero ciertas situaciones se producen y estas crean nuevos derechos y estados" en caso de una guerra civil. Urrutia (1928:270) muestra cómo las guerras civiles afectan el Derecho Internacional, tomando como ejemplo la guerra civil norteamericana, 
como que los Estados están obligados a usar todos los medios y deberes "para evitar que los habitantes de su territorio tomen parte en una guerra civil, y desarmar toda fuerza rebelde que pase sus fronteras y a prohibir el tráfico de armas" y "a evitar que dentro de la jurisdicción sea equipado, armado y adaptado al servicio de guerra, toda embarcación destinada a operar dentro del interés de la rebelión" (fiel síntesis de la Sexta Conferencia Panamericana). El gran peligro recae, para Rougier y Urrutia, en que los rebeldes pueden contraer el carácter de beligerantes, además de los subsecuentes reconocimientos a los gobiernos recién constituidos por los rebeldes.

Sin embargo, cuando Rougier concluye el pasaje referente a Colombia, en el que asume que una "guerra civil es una forma diferente de la guerra internacional", tampoco se atreve a darle un contorno específico, fruto de su propio análisis. Quizás esta labor quedaría reservada para los internacionalistas e historiadores de las décadas posteriores: ¿se podría hablar de una "guerra civil internacional»?, término de una literatura más reciente. La principal condición para que se considere tal categoría, es, como diría Hobsbawm (1997), que adquiera un carácter «ecuménico», aunque no sea necesario que llegue a ser universal. Otra, que efectivamente no adquiera el contorno de una guerra interestatal, sino más bien entre diferentes ideologías. En ambos casos, las guerras civiles colombianas cumplen parcialmente semejantes atributos. Sin embargo, como ocurriese con una guerra civil internacional ecuménica por excelencia, esto es, la fase expansiva de la Revolución Francesa, en el caso colombiano la internacionalidad de las guerras civiles no estuvo marcada por la exportación de un modelo universal revolucionario, sino que más bien soportaba el ideal de un liberalismo internacional desde afuera con el fin de legitimar o encausar la contienda; esto fue particularmente verídico durante el periodo 1895-1903 en el caso de los rebeldes liberales, que buscaron el apoyo de regímenes liberales establecidos en Venezuela, Ecuador, Centroamérica y otras zonas. Si existen elementos de una guerra civil internacional, estos se deben más a factores exógenos que a una relación de hechos que incluyen desde la acción de algún actor político establecido en el poder hasta la puesta en marcha de un programa «nacional» de expansión de ideales revolucionarios. Por ahora, seguiremos creyendo que se trata de una guerra civil, a secas, pero afectada por las fuerzas profundas y las relaciones internacionales.

Del mismo modo, las relaciones internacionales de América Latina durante el periodo 18801914 estuvieron fuertemente acuciadas por el embate del imperialismo. Sin embargo, a diferencia de otras zonas del globo, como Asia y África, las pretensiones imperialistas hacia América Latina encontraron un eco favorable en los proyectos de injerencia interna a través de la incorporación de capital, instituciones culturales y de las guerras civiles. Secreto o no, el hecho es que casi todas estas revoluciones estuvieron ligadas al meteórico ascenso de Estados Unidos como gran potencia y su subsecuente participación en cada una de ellas. La "diplomacia del dólar" norteamericana entendía que era más barato conquistar mercados a través del fomento 
del desorden, que una lisa y llana política de conquistas coloniales (Lafeber, 1995). Además de los casos de Nicaragua, Cuba y Panamá, otras regiones de América Latina vieron de frente las pretensiones del poder norteamericano. Este sería el caso de Chile:

\footnotetext{
"El ascendiente estadounidense se manifestó también en su intervención en Chile, donde una guerra civil enfrentó a sectores conservadores contra el presidente reformista José Balmaceda. La sospecha de que Estados Unidos ayudaba a Balmaceda provocó en octubre de 1891 un ataque del populacho de Valparaíso contra varios marineros del USS Baltimore, que estaba en el puerto. El nuevo gobierno chileno rechazó airadamente la demanda estadounidense de reparaciones, plegándose a pagar una indemnización de 75.000 dólares sólo ante la amenaza del presidente Harrison de emplear la fuerza" (Hilton, 2001:103).
}

Semejante "diplomacia", hizo a Estados Unidos crear diversas formas de legalidad, como el arbitraje, que además de buscar detener la Guerra del Pacífico (1879-1884), por medio del Presidente Blaine (Blaine consentía la no propagación y apoyo a las guerras de expansión, buscaba apoyo iberoamericano para la Conferencia de Washington), o el panamericanismo (Primera Conferencia Panamericana de Washington de 1889) para promover los intereses comerciales en América (Hilton, 2001:100).

Aunado a todo este esfuerzo norteamericano, los países de América Latina también tuvieron serias intenciones o de repeler este impulso colonialista o de aventurar se a pequeñas conquistas territoriales sobre sus países vecinos. La Guerra de la Triple Alianza (1864-1870), en la que Uruguay, Argentina y Brasil lucharon contra Paraguay, o la citada Guerra del Pacífico, eran un buen ejemplo de ello. Aunque puede considerarse estrictamente una guerra-estatalinternacional, la de la Triple Alianza también tuvo un carácter de guerra civil clandestina en contra del gobierno paraguayo de Solano López, combatido por la oposición y los gobiernos vecinos que apoyaron a los rebeldes paraguayos; a diferencia del caso colombiano, como veremos, este sobresalió por arrojar un nuevo mapa político regional, especialmente porque Argentina adquiere territorios fronterizos en Misiones y Chaco. En sentido estricto, otro tipo de guerras (más bien clandestinas) eran motivadas por una guerra civil al interior de uno de los estados, en la cual participaban fuerzas oficiales de un país vecino con el fin de asegurar su interés nacional o simplemente para preservar su fuero constitucional. Este sería el caso de Colombia, que en las tres guerras civiles aquí presentadas $(1885,1895,1899)$, estuvo a punto de ir a una guerra internacional y otras veces rompió relaciones diplomáticas, con Ecuador y Venezuela. A diferencia de otras guerras regionales, las de Colombia sobresalen por tener un carácter ideológico, partidista y clandestino; pero por trascender las fronteras y contar con la injerencia de algunos estados, por esto, deben considerarse literalmente no estatales/ internacionales, aunque tampoco como una guerra civil internacional, puesto que no cumplen con los requisitos atrás señalado. 


\section{LA DIPLOMACIA SECRETA DE COLOMBIA FRENTE A ECUADOR Y VENEZUELA}

En términos generales, pudimos encontrar que durante este periodo las relaciones internacionales de Colombia estuvieron marcadas por las guerras civiles, por un lado, y la diplomacia pragmática frente a Estados Unidos con la cuestión en torno al Istmo y todos sus contornos alrededor de las guerras civiles, por el otro. Este segundo aspecto lo trataremos más adelante. En cuanto al primero, en la guerra civil de 1885, se tuvo noticia de que en un combate de Cúcuta, que dejó 800 muertos, el vecino Estado de Táchira, prestó ayuda y tropas para la invasión de Colombia. Rafael Reyes, entonces general colombiano, envió un mensaje amenazante al Presidente de Venezuela, General Crespo: "qué actitud tomaba el gobierno venezolano con respecto a la bárbara y salvaje invasión [...]", a lo que él mismo respondió que "iríamos a esperar la respuesta a la frontera del Táchira" (Carta de Rufino José Cuervo a Antonio Gómez Restrepo, 10 de marzo de 1895, en Epistolario, 1973:88-89). Las relaciones del gobierno conservador colombiano con el régimen nacionalista-militar venezolano, a la cabeza de Crespo, habían sido normales desde 1879, después de cuatro años de ruptura a causa de innumerables informes que acusaban al gobierno colombiano de invasiones tras invasiones al territorio vecino por sus guerras civiles (Informe del Secretario Pablo Arosemena, 1879, en Anales, IV, 1914:13-14).

Desde la última administración de Mosquera, el tratamiento hacia Venezuela había estado supeditado a una posible invasión, puesto que para el gobierno colombiano era insoportable la tensión que producían los "intereses económicos", los impuestos a mercaderías colombianas y la irreducible posición venezolana respecto a sus fronteras (Rivas, 1961:437-438). Según Rivas (1961:460-461), “La guerra civil que afrontaba Venezuela contribuía a aumentar la tirantez de relaciones, por la complicación inherente al cumplimiento de la policía de fronteras y el desarme e internación de asilados". Tanto en 1875, 1879 y 1885-1886, las relaciones entre Colombia y Venezuela tuvieron que ser resueltas a través de Protocolos secretos y agentes confidenciales que prometieron, entre otras cosas, buscar un Laudo Arbitral para resolver el problema fronterizo, internar revolucionarios en la zona fronteriza a una distancia considerable de su país de origen (en algunos casos encarcelaros o extraditarlos), asegurar la neutralidad y, más importante, reforzar el tratado de cooperación, amistad y comercio de 1842 (ver Anales, II, 1901:118). Razón de sobra pragmática.

Como se ve, el problema radicaba básicamente en "intereses económicos" y "fronterizos", a diferencia de las dos guerras civiles posteriores (1895 y 1899), donde la sustancia estaba definida por una cuestión de honores partidaristas. En el caso de Ecuador, también las relaciones estaban fuertemente deterioradas desde 1876, por más que siempre las Legaciones, en sus habituales discursos de acreditación, hablasen de la eterna amistad entre dos naciones hermanas. La frontera colombo-ecuatoriana vivía en un permanente estado de exaltación y 
de alarma, que si bien pueden corroborarse, la mayoría de las veces eran producto de noticias falsas e incendiarias (Anales, IV, 1914:14-15). Después de la guerra civil de 1876, en Tulcán aparecieron colombianos revolucionarios, que sin más fueron acusados de violar el territorio ecuatoriano. El momento crítico de las relaciones llegó cuando en 1878 fueron heridos varios colombianos en unos sucesos de Riobamba, a lo que el gobierno colombiano solicitó una indemnización completa. Dadas las condiciones, el Estado colombiano amenazó nuevamente con una invasión. Para fortuna de ambos, la solución se consiguió por medio de un arbitraje en 1879, celebrado en Quito (Rivas, 1961:462-463).

La guerra civil de 1876 dio la pauta para el tratamiento del Derecho Internacional hasta que concluyó la guerra de 1899-1903. Incidentes relacionados con el orden público, los derechos y deberes de los extranjeros y las indemnizaciones a que éstos pudieran tener derecho, fueron incluidos en los diversos protocolos firmados para tal efecto. Tales fueron las palabras del Secretario de Relaciones Exteriores, don Pablo Arosemena, en 1879: "sólo el mantenimiento del orden y el cumplimiento de las leyes internacionales por largo tiempo creará en esos pueblos el estado de confianza y seguridad que exigen el interés y el honor de los dos países" (Anales, IV, 1914:14). En esta vía, el gobierno colombiano envió un Batallón con instrucciones de "guardar la neutralidad más estricta en los asuntos internos de dicho Estado" (Anales, IV, 1914:15). Más tarde, durante la guerra civil ecuatoriana de 1882, Colombia tuvo el delicado gesto de enviar un Contingente para garantizar la neutralidad. El gobierno ecuatoriano siempre admitió las buenas intenciones de Colombia, y de paso su sinceridad. Pero ambos reconocían que "contribuyeron a impedir este resultado la inmensa extensión de la frontera, abierta por todas partes [...]; la facilidad de comunicación, y la simpatía y aun entusiasmo que reina en la opinión pública de los pueblos fronterizos de Colombia por la causa revolucionaria del Ecuador" (Informe del Secretario Quijano Wallis, 1883, en Anales, IV, 1914:231).

En su publicación de 1936, Raimundo Rivas (1961:518-519), reseñó acertadamente que con la guerra civil de 1885 se estaba experimentando un cambio profundo en la percepción de la política exterior colombiana:

"La guerra civil de 1885, que tan fundamental cambio efectuó en las instituciones políticas del país, al sustituir un federalismo exagerado con un rígido centralismo, determinó igualmente modificaciones en la orientación y métodos de la política internacional de Colombia".

Efectivamente esto se demostró en el tratamiento a la ley de extranjeros. Desde la Constitución de 1863 se había estado buscando la mejor manera de incorporar una ley de extranjería con el doble propósito de verificar daños o perjuicios por las guerras civiles en contra de los extranjeros, y en torno a sus derechos civiles como residentes en la nación colombiana. La doctrina colombiana hasta más o menos 1885 referente al tratamiento de extranjeros afectados por las 
guerras civiles era sencillamente que no se hacía responsable ni reconocía ninguna indemnización por expropiaciones (Caicedo Castilla, 1974:309). Sin embargo, con la argucia de la potencias europeas y norteamericana, Colombia terminó cediendo a sus imposiciones, que bajo la cortina de la legalidad inscribió la nueva doctrina de un tratamiento igualitario tanto a extranjeros como a nacionales. La Ley 67 de 1877 lo ratifica. Varios doctos del Derecho Internacional de finales del siglo XIX parecen haber sugerido al Gobierno colombiano adaptarse a los principios de responsabilidad e irresponsabilidad del Estado en los casos de perjuicios a extranjeros durante la guerra civil. En su "Estudio sobre la guerra civil", tesis de 1896 para optar al título de Doctor en Derecho, Pedro Carreño Arjona adujo que los gobiernos no son responsables en los casos en que los extranjeros tomen parte por el bando rival del Estado, y que aun deben ser considerados "extranjeros perniciosos" que deben ser expulsados del territorio. El principio de irresponsabilidad también es aplicado en los casos en que el Estado se ve forzado a expropiar bienes de extranjeros o nacionales para financiar el curso favorable de la contienda. ¿En qué casos es el Estado responsable? Según Carreño, el artículo 11 de la Ley 145 de 1888, sobre extranjeros, no lo es en ningún caso, exceptuando los Tratados Internacionales que se efectúen al respecto (ver esta tesis en Anales, I, 1900:261-263).

A decir verdad, el Estado colombiano hizo más bien caso omiso a todos estos preceptos de juristas internacionales y del propio Derecho Internacional reinante en la época. Bien lo reseñó el académico Caicedo Castilla (1974:310):

\footnotetext{
"[...] las reclamaciones dieron lugar a la expedición de varias leyes que se modificaban sucesivamente ante las peticiones extranjeras. Luego el Ejecutivo sometió algunas de aquellas a arbitraje, lo cual desconocía la igualdad de trato entre nacional y extranjero, pues el último se sustraía a la jurisdicción de los tribunales ordinarios. Finalmente, los tribunales arbitrales se constituyeron aceptando como tercero en discordia a nacionales o diplomáticos de potencias europeas o de los Estados Unidos. Naturalmente esto desvirtuaba hasta cierto punto la imparcialidad del fallo arbitral".
}

Entre 1882 y 1890, Venezuela y Ecuador se eximieron de indemnizar a extranjeros en casos de guerra civil, por lo que Colombia protestó (Informe del Secretario de Relaciones Exteriores, Antonio Roldán, 1890, en Anales, IV, 1914:501). Inútiles tales protestas, el Estado colombiano acentuó más sus preocupaciones en los casos de extranjeros provenientes de potencias europeas. Bien no habían terminado los problemas con los Estados que sostenían relaciones diplomáticas con Colombia, cuando se tenían que asumir otras situaciones de carácter urgente; el tratamiento a extranjeros que eran expropiados durante las guerras civiles trajo como consecuencia la intervención de las potencias en defensa de sus ciudadanos. En términos generales se puede inferir que detrás de cada migración venían los intereses de sus países de origen. Los incidentes con los extranjeros obligaron al gobierno colombiano a crear leyes y convenios especiales para el tratamiento de los extranjeros, con un interés o intención explícita 
en torno a las potencias (Caicedo Castilla, 1974:308-310, 373 y ss.; cfr. Urrutia, 1928:295298). De los múltiples casos encontrados, sobresalió el del italiano Cerruti y su supuesta participación a favor de los rebeldes liberales radicales del Valle del Cauca en 1884-1885, controversia que se extendió hasta 1897. Después de largos intentos de mediación (española), arbitraje (norteamericano) y la suavización de la postura colombiana al devolver todos los bienes incautados a Cerruti, lo más importante de todo este periplo fue el conato de guerra que estuvo a punto de emerger entre Italia y Colombia, que se disolvió gracias al arbitraje de Estados Unidos en 1897 (Informes del Secretario de Relaciones Exteriores, 1888, 1897, en Anales, IV, 1914:336, 416-433, 529-545, 607, 717-718).

Colombia siempre asumió una posición legalista, pero práctica y realista, hasta el punto que tuvo que ceder en el cambio favorable hacia los extranjeros relativo a las leyes de extranjería: la indemnización por guerras civiles se resolvería vía administrativa y no judicial, además que se dejó en pie de desigualdad jurídica a nacionales y a extranjeros (Caicedo Castilla, 1974; Rivas, 1961:480-481, 486). Hasta que se resolvió el caso Cerruti, el estado colombiano había aceptado las normas comunes del Derecho Internacional sobre el tratamiento a extranjeros, es decir, concederles un trato de igualdad con los nacionales, exceptuando los créditos de guerra y algún derecho político momentáneo. Todas las naciones «civilizadas» sabían de sobra que sus ciudadanos tendrían que correr riesgos fuera de sus países. Admitían, de paso, que sus ciudadanos tendrían que ser tratados bajo el ropaje del sistema judicial local. Pero además de no confiar a carta cabal en el sistema judicial colombiano, las potencias veían la oportunidad perfecta para justificar sus políticas expansionistas, por medio del desorden suscitado por las guerras civiles. El caso Cerruti sentó las bases para una nueva doctrina sobre el tratamiento a extranjeros, que el Estado redefinió con una justa dosis de pragmatismo y celeridad diplomáticos.

La guerra civil de 1885 también produjo ásperos debates diplomáticos. Existe un caso particular, sensiblemente crítico. Se trata de una posición que asumió el Estado colombiano con relación a las doctrinas del derecho diplomático y consular. El gobierno colombiano expidió una circular que aclara su posición sobre el derecho de asilo que solicitaron algunos colombianos en la Embajada de Argentina durante la confrontación de 1885; en tal comunicado adujo: "La doctrina sostenida por el Gobierno se reduce á consignar al derecho de asilo toda la amplitud compatible con los fueros de la soberanía con los derechos de conservar el orden público y prevenir y castigar los delitos, facultad que es inmanente á todo Gobierno" (Informe del Secretario de Relaciones Exteriores, Vicente Restrepo, 1885, en Anales, IV, 1914:342). Colombia, en poco, estaba solicitando la aprehensión de tales liberales que se asilaron en la Embajada de Argentina. Convencidos de lo contrario, y estupefactos por la avergonzante posición colombiana, los embajadores de Chile, Ecuador, Estados Unidos, Gran Bretaña, Francia y España, respondieron con una negativa penosa, que inducía a una violación clara del derecho 
diplomático vigente entonces (Anales, IV, 1914:343-344, 346-347). La Embajada de Argentina, la directa implicada, dice que, tomando una posición media, enviará el caso a su gobierno, pero que se muestra apenada por la actitud del gobierno colombiano (Anales, IV, 1914:350). Colombia, a pesar de notificar unas disculpas más bien obligantes, reconoció que debía hacer más averiguaciones (casi todos estos hechos eran referenciados por rumores o informes de inteligencia inacabados), pero, en ningún momento, hasta 1903, dejó de alegar sus fundamentos civilistas. En tal sentido, el entonces Secretario de Relaciones Exteriores, don Marco Fidel Suárez, en 1892, (Anales, IV, 1914:602) reafirmó la posición del Estado en torno al carácter internacional de las guerras civiles. Vale la pena transcribir su alegato:

\footnotetext{
“Dicho concepto no tuvo el carácter de una guerra obligatoria, sino el de una teoría más o menos probable. Consiste en distinguir entre el derecho de conceder el asilo y el deber de respetarlo; en restringir aquel derecho á los casos de persecución injusta en que corra riesgo la vida del asilado; en no admitirlo en ningún caso contra la acción ordinaria de la justicia; en atribuir exclusivamente al gobierno de la Legación que lo otorga la facultad de limitado; en obligar al gobierno del asilado á respetar el asilo, salvo los caso en que éste asuma tales proporciones que amenace el orden público; y en establecer como solución de esos conflictos, no el choque entre el derecho de conceder el asilo y el deber de respetarlo, sino la acción armónica de los gobiernos para limitar en la práctica esta institución á fines justos y humanitarios".
}

El terreno estaba abonado o bien para mantener unas relaciones diplomáticas tensionantes o bien para posibilitar el ascenso de revueltas liberales nacionales y extranjeras. El periodo 1895-1903 arrastró consigo mismo las dos posibilidades. Desde la crisis cubana de 1895, la ideología liberal en América Latina tomaba cada vez más forma y conseguía cada vez más afianzarse en los gobiernos nacionales. Venezuela y Ecuador, directos implicados en las guerras civiles de Colombia, tenían la visión de una América Latina liberal, racional y laica (masona). Antes de asumir el poder ecuatoriano en 1895, Eloy Alfaro, ya contaba con que el “Presidente Antonio Guzmán Blanco y los Generales venezolanos Joaquín Crespo e Ignacio Andrade, liberales como él, lo tenían en gran estima y no sólo le brindaron su afecto, sino ayuda económica para sus campañas en el Ecuador" (Santos Rodríguez, 1995:35; Loor, 1947:610). Entre 1895 y 1902, Alfaro emprendió la lucha liberal a favor de Cuba (con Martí y Maceo), la confederación de América Central (con Santos Zelaya, Rufino Barrios y Francisco Morazán), el apoyo irrestricto a los liberales colombianos y la tarea de reformar la Gran CoIombia, junto con Rafael Uribe Uribe y Cipriano Castro. Cuando se juntaron Castro y Alfaro, el gobierno colombiano se vio en serios aprietos. Parecía que todo estaba listo para la perpetuación del liberalismo radical en América Latina.

Por una parte, la consecución de los recursos casi siempre obedecía a las posibilidades reales de triunfo que ofrecieran los rebeldes a los estados benefactores. Más allá de la ideología 
internacional que estos actores justificaban, como las simpatías entre liberales y conservadores de todos los países involucrados, existían también intereses materiales o prácticos que justificaban el apoyo mutuo (D.M.P., 1904:185, 204, 216, 440-441; Tamayo, 1938:188-190; Durán, 1920:125; Caballero, 1939:75, 79-80; Salazar, 1992:245). Entre los diversos intereses ideológicos, por así llamarlo, sobresalían sobre todo las simpatías de los movimientos liberales internacionales, independentistas, como el caso de Cuba en 1899, y, en especial, los radicalismos democráticos que estaban en boga en todo el Atlántico, en contravía de los conservadurismos monárquicos de Europa, y los regímenes conservadores, nacionalistas y oligárquico-militaristas de América Latina (Urrutia, 1920; D.M.P., 1904).

Hubo, sin embargo, un acápite especial en estas circunstancias ideológicas: durante el periodo 1885-1903 existió un fuerte apego a la idea de retornar a la gran nación colombiana, inaugurada por Bolívar en 1819-1821 (D.M.P., 1904:204), extinguida en 1830 y en ebullición durante los decenios 1850-1870, idea que, por lo demás, había sido curiosamente diseminada por liberales colombianos y venezolanos (Fuenmayor, 1984, I:72-73; Carrera Damas, 1987). Alfaro pidió al Congreso ecuatoriano en 1898 poderes para negociar con Colombia y Venezuela la creación de la Confederación Grancolombiana; denegada su solicitud, "los liberales colombianos residentes en Quito lo designaron, a mucha honra, con el alto valor simbólico: 'Director Supremo de la Confederación Grancolombiana'" (Santos Rodríguez, 1995:45).

Los conservadores ecuatorianos, venezolanos y colombianos no tardaron en tachar este proyecto de antipatriótico, pues se trataba "de borrar nuestras actuales nacionalidades, de suprimir los nombres queridos de Venezuela y Colombia para envolverlos en un todo que sirviera de escabel a sus miras ambiciosas" (Manifiesto de Rangel Garbiras, 1901:76, en el Boletín del Archivo Histórico de Miraflores, No. 5). Carlos Rangel Garbiras era el asilado venezolano radicado en Colombia más importante de la resistencia armada contra Cipriano Castro. Poco después el propio Castro pedía en una carta privada que "Como circula aquí hoy una contestación brillante de Galavís al manifiesto estúpido de Rangel”, lo mejor sería publicarla y estropearla (Carta de Cipriano Castro a Celestino Castro, 24 de julio de 1901, en Boletín del Archivo Histórico de Miraflores:78). ¿Cuáles eran las verdaderas intenciones de reformar la Gran Colombia? ¿Estarían dispuestos Alfaro, Castro y Uribe Uribe a sacrificar nuevas y cruentas guerras civiles con tales fines? Tal parece que esta era una idea filoromántica de algunos líderes liberales, y que la mayoría de los concejos municipales, distritos y capitales importantes veían esta iniciativa como algo sardónicamente absurdo. En una investigación exhaustiva, Thomas Allen Pitt encontró que en el telón de fondo de la reconstitución de la Gran Colombia había múltiples intereses materiales, sobresaliendo el referente a la definición de la frontera colombo-ecuatoriana, desvirtuada por una alianza secreta concebida entre Perú y Colombia para arrebatarle territorio a Ecuador (Allen Pitt, 1976:31-44). El propio Alfaro, en varios comunicados reconocía la debilidad de Ecuador y su inoperancia estatal para preservar la 
soberanía nacional, ante la eventual absorción tentacular de Colombia y sus múltiples amenazas de invasión militar (Santos Rodríguez, 1995; Loor, 1947; Pareja Díez-Canseco, 1944; Andrade, 1935). Qué mejor remedio que una alianza confederada con sus aliados liberales de Venezuela y Colombia, y sus amigos de Centroamérica y Cuba.

Pero también existían otros intereses materiales claramente definidos. El mismo General Rafael Uribe Uribe, en su Manifiesto de abril de 1901, reconoció que además de las ideas, la ideología internacional del liberalismo, debe manifestarse con ingentes recursos puestos a la mano por los "gobiernos amigos" y los colombianos que defienden la Causa del liberalismo (Uribe Uribe, 1901, en D.M.P., 1904:185-186). El gobierno conservador de transición de 1901 acusó al gobierno liberal venezolano, representado por Cipriano Castro, de ser un instigador de los rebeldes colombianos por puro y llano interés: "el Presidente Castro [sostenía Pedro Nel Ospina], que sentía desquiciarse su poder pocos días antes, se halló repentinamente, y por causa de aquella aventura [la batalla del Táchira de 1901], rodeado de opinión y de fuerza" (D.M.P., 1904:211). Uribe Uribe, por su parte, hacía el contrapeso liberal: "ni es que cuando para combatirnos no vacilan nuestros enemigos en sacrificar la prórroga de la concesión del Canal, la prolongación del Ferrocarril de Panamá, y aun acaso, á la hora presente, el propio Istmo, á trueque de miserias para exterminarnos" (Carta de Uribe Uribe a Juan Antonio Hernández y Teodosio Sánchez, 1901, en D.M.P., 1904:217). Lo mismo ocurría con los presidentes liberales de Nicaragua, Santos Zelaya, que apoyó la invasión de Panamá desde Centro América (incluidos El Salvador y Guatemala), y el Presidente liberal de Ecuador, Eloy Alfaro, quien apoyó a los rebeldes desde el norte de ese país y llevó a una guerra clandestina en 1900 entre conservadores colombianos y ecuatorianos y liberales de ambos lados, como veremos; todo con el fin de desestabilizar el régimen conservador colombiano, claramente la potencia regional más poderosa de entonces, que incluso tenía el plan secreto de incorporar Costa Rica a su territorio (Borda, 1974; D.M.P., 1904:416; D.O., 1900:469-470; Anales, 1914:741-749; Loor, 1947; Pareja Díez-Canseco, 1944; Andrade, 1935).

Desde entonces se entrecruzaron diversas misivas violentas entre los gobiernos de Ecuador y Venezuela hacia Colombia. La reclamación del Ecuador, que venía ajustándose desde 1885, dejó entrever que la cuestión no se trataba únicamente del apoyo de funcionarios locales radicados en la zona de frontera; también envolvía directamente al gobierno nacional por su apoyo decidido a las fuerzas católicas del Ecuador (Legación del Ecuador, Bogotá, mayo 27 de 1885, en A.G.N., F.M.R.E, Archivo Diplomático y Consular). La paradiplomacia ecuatoriana se vio claramente reflejada en diciembre de 1895: el propio Alfaro contactó a un venezolano más bien misterioso y errante radicado en París, con la intermediación de su Cónsul, para la compra de diez mil fusiles Mausser con sus bayonetas, tres millones de cartuchos y unas mil carabinas. Alfaro fue estafado por el misterioso venezolano, ya que los fusiles que llegaron a Ecuador eran del calibre Mánlicher; una vez radicados en Esmeraldas, fue patente que sus 
destinatarios colombianos tenían que compensar la gratitud del caudillo ecuatoriano con una gran derrota a las fuerzas conservadoras de Colombia (Loor, 1947:615). Derrotados los liberales en Sanancajas, Alfaro temió una invasión colombiana que de paso arrastraría consigo y su Gobierno las fuerzas de los católicos de uno y otro lado del Carchi.

El gobierno liberal del Ecuador asumió entonces una actitud de neutralidad y pasividad ante la magnitud de los hechos. Más aún: reconoció la necesidad de firmar un pacto de alianza con el gobierno conservador colombiano, a lo que el Presidente Caro le notificó que también era su deseo, con base en una amistad franca y justiciera. Pero todo indica que la actitud colombiana frente al gobierno del Ecuador ni fue franca ni fue justiciera. En 1899, la Legación del Ecuador en Bogotá envió la siguiente misiva:

"En nuestras varias y cordiales conferencias, he tenido el honor de hablarle, extensamente, acerca de los inmensos daños y perjuicios que, de tres años á esta parte, viene recibiendo mi Patria con las frecuentes invasiones armadas, procedentes del territorio colombiano" (Legación del Ecuador, Bogotá, abril 24 de 1899, en A.G.N., F.M.R.E, Archivo Diplomático y Consular).

Esta fue la respuesta de la Cancillería colombiana: si bien

“[...] los revolucionarios del Ecuador han podido encontrar simpatías y apoyo subrepticio en territorio colombiano, á despecho de la acción de nuestras autoridades, esto depende, como bien lo sabe Vuestra Excelencia, de las dificultades, á menudo insuperables, que ofrece la vigilancia de una frontera tan extensa, habitada de un lado y otro, por gentes a quienes ligan vínculos de amistad [...]".

Seguían denunciando

"[...] la dificultad en que se encuentran las autoridades colombianas para establecer una separación absoluta entre los habitantes de las poblaciones fronterizas, en todo cuando á la política se refiere" (Ministerio de Relaciones Exteriores, Bogotá, 13 de mayo de 1899, en A.G.N., F.M.R.E, Archivo Diplomático y Consular).

En el mismo comunicado el gobierno de Colombia aseguró cumplir con la neutralidad que se requería y afirmó que castigaría a los funcionarios de la frontera con destitución y encarcelamiento; a los ecuatorianos asilados o enganchados con fines revolucionarios en territorio colombiano los internó en una distancia bastante retirada de la frontera, de acuerdo a los mandatos de la policía de frontera vigentes entonces. Ecuador manifestó su agradecimiento ante semejante actitud. Sin embargo, entre mayo y octubre de 1899, es decir, antes de que estallara la Guerra de los Mil Días, la situación no cambió mucho. Esto se puede inferir del comunicado de la Legación del Ecuador, en respuesta al comunicado colombiano: 
“Es muy cierto, Señor Ministro, que una frontera tan extensa, como la que existe entre ambos estados, presente al Gobierno de Vuestra Excelencia grandes dificultades para vigilar, pero igualmente lo es que siendo el mismo inconveniente común al Ecuador, este, lejos de perturbar la paz de Colombia, recibe de ella frecuentes invasiones armadas".

Además,

"Las autoridades fronterizas saben muy bien distinguir á los unos de los otros, Señor Ministro, por mucho que ellos para disculparse digan lo contrario al Gobierno Central. Los primeros son, generalmente, residentes en el Ecuador, ó cuando pasan la frontera lo hacen en plena paz y á la luz del día, como que van á desempeñar un cargo honorable. Los segundos son conspiradores consuetudinarios é incorregibles, perfectamente conocidos en las Provincias del Sur, secundados por autoridades inferiores que no cumplen las órdenes del Gobierno de Colombia" (Legación del Ecuador, Bogotá, mayo 23 de 1899, en A.G.N., F.M.R.E, Archivo Diplomático y Consular).

Alfaro encontró con la Guerra de los Mil Días el lugar indicado para acentuar su mezcla de venganza, engrandecimiento por el triunfo de Castro en Venezuela y el ascenso de la masonería en Ecuador. El General Alfaro llegó a un estado de megalomanía y paroxismo tal que en 1899 emprendió el apoyo y dirección de la revolución colombiana contra los "títeres de divisa azul" (Loor, 1947:618).

Algunos hombres de gran dilación, como el General Herrera, el comerciante Manuel de Jesús Andrade, Vicente Chaux, Lucas Caballero, entre otros, parecían simples lugartenientes de Alfaro, que recibían órdenes y pertrechos a través de Esmeraldas, provincia fronteriza con Colombia. Manuel de Jesús Andrade, en su "Andanzas de un Colombiano" (1935:135, 139), alardeaba de su condición de talla presidencial (o mejor, de su amistad personal con Alfaro), comisionado para formar "algo como un triunvirato revolucionario en Guayaquil", junto con "el Coronel Flavio E. Alfaro, jefe militar de todo el litoral; el ex ministro de estado, político y periodista José de Lapierre y yo, graduado por los primeros con el fuero de representante nato de la revolución colombiana". Los liberales, que en todas partes anunciaban el triunfo de Barbacoas como paso glorioso para tomarse Pasto y Popayán, fueron derrotados nuevamente en Ipiales. Tomarse el Cauca era algo así como tomarse media República. Peor aún: en marzo de 1900 los liberales colombianos y ecuatorianos recibieron una derrota estrepitosa en la batalla de Tulcán.

En menos de nada las tropas colombianas se habían tomado la zona fronteriza de Ecuador. Las relaciones entre el régimen conservador de Colombia y el liberal de Ecuador fueron aun más tensionantes con la renombrada "Invasión Colombiana" de 1900, en respuesta al apoyo de Alfaro a los liberales colombianos de la frontera con más de 600 fusiles, un cañón del vapor 
Cotopaxi y más de 200 tropas de ecuatorianos liberales (el término "Invasión Colombiana es de Loor, 1947:613-628; Andrade, 1935:139). Como todas las invasiones colombianas, el apoyo ecuatoriano fue también clandestino. De todos los consulados colombianos y ecuatorianos iban y venían telegramas secretos que contrariaban los comunicados y notas de cancillería, aduciendo que los gobiernos nacionales estaban respetando la neutralidad y la ley de policía de fronteras (A.G.N., F.M.R.E., Libro No. 116, 1898-1901, "Revoluciones del Ecuador y de Colombia"). El 15 de junio de 1900, aunque no se rompieron las relaciones diplomáticas, se firmó el Protocolo entre Colombia y el Ecuador en que se aseguraba guardar los deberes fronterizos de neutralidad, vigilancia y policía de fronteras (D.O., 3 de julio de 1900:469). Promesas falsas. Entre julio de 1900 y diciembre de 1902, siguieron entrecruzándose los mismos desvaríos liberales y conservadores tal y como sucedió antes de la firma del Protocolo (Telegramas del Consulado colombiano en Guayaquil, A.G.N., F.M.R.E, Archivo Diplomático y Consular; Loor, 1947; Andrade, 1935; Allen Pitt, 1976). Lo único que concluyó semejante desfile de guerra informal fue la misma terminación de la guerra civil.

Con relación a Venezuela, las cosas Ilegaron a un extremo asaz delicado: se rompieron las relaciones diplomáticas en 1901 y se llegó incluso a propagar la idea de una guerra internacional. Al igual que con el Ecuador, el Estado venezolano tenía el temor de una invasión colombiana dirigida por los "godos". Desde octubre de 1900 hasta julio de 1901, cuando se libra la batalla clandestina entre fuerzas conservadoras colombianas y venezolanas contra el régimen de Castro, todas las noticias se tenían por conducto de espías en cada lado de la frontera (Carta de Celestino Castro a Cipriano Castro, San Cristóbal, octubre 5 de 1900, Boletín del Archivo Histórico de Miraflores, No.5:59). Mientras esto ocurría, el gobierno colombiano seguía afirmando que mantenía la neutralidad frente al estado de conmoción interna en Venezuela. En tal sentido se expresaba Cipriano Castro:

“El Gobierno se ocupa activamente de resolver esos asuntos con el Excelentísimo señor Ministro de Colombia residente aquí en Caracas, y le ha propuesto al efecto por repetidas veces, ya de palabra, ya por escrito, que procedan los dos Gobiernos simultáneamente a internar los asilados, respectivamente, de las dos Repúblicas, perturbadores del orden público, que comprometen sus intereses, como único recurso satisfactorio para evitar el mal, pero nada se ha podido conseguir hasta hoy" (Carta de Celestino Castro a Cipriano Castro, San Cristóbal, julio 23 de 1901, Boletín del Archivo Histórico de Miraflores, No.5:75-76).

En efecto: nada se pudo conseguir. En julio se había verificado la invasión de tropas colombianas al Estado de Táchira, concebida como una "audaz violación de la soberanía y la integridad nacional" (Carta de Celestino Castro a Cipriano Castro, San Cristóbal, julio 26 de 1901, Boletín del Archivo Histórico de Miraflores, No.5:79). Los liberales colombianos, al mando de Uribe Uribe, parecían más bien una prolongación del Directorio Restaurador venezolano, que seguían 
incluso las órdenes del propio Castro (ver, por ejemplo, Cartas de Celestino Castro a Cipriano Castro, San Cristóbal, julio 26 de 1901; agosto 24 de 1901, Boletín del Archivo Histórico de Miraflores, No.5:82, 101). Castro ofreció todo tipo de apoyo militar y enganches para los combatientes colombianos en la batalla de Táchira y las del Magdalena, Panamá y Cundinamarca, tal y como lo hizo Alfaro en las Provincias del Sur.

El 16 de agosto de 1901, el gobierno venezolano expidió un Memorándum que le mostraba a todo el mundo civilizado las razones por las cuales se suspendieron las relaciones diplomáticas y comerciales con Colombia. Aducía, entre otras cosas: "violación del territorio por fuerzas colombianas con un revolucionario venezolano á la cabeza [Rangel Garbiras]", y, falazmente, afirmaba que el gobierno fue sorprendido "doblemente, pues fuera de no haber indicio alguno material que pudiera haberlo anunciado, las circunstancias mismas en que se hallaba la República y el estado favorable de las relaciones con el país vecino, hacían imposible, no ya la previsión de acto tan insólito, sino aun la de un movimiento producido únicamente por asilados venezolanos" (D.O., Documentos relativos á la suspensión de relaciones diplomáticas entre Colombia y Venezuela, 25 de agosto de 1901:805).

Ante tales acusaciones, el Gobierno de Colombia responde de manera enérgica, previo aviso de la descortesía diplomática de Venezuela, ya que el gobierno colombiano sólo tuvo conocimiento del Memorándum a través de la prensa extranjera. Colombia adujo, en primer lugar, que Venezuela fue el primero en auxiliar a rebeldes liberales en la frontera; que la población vecina de Cúcuta fue invadida con apoyo de autoridades venezolanas; que Venezuela auxilió, refugió, enganchó y asiló a los rebeldes para la toma de Casanare en diciembre de 1900; permitió el arribo de un Vapor para los rebeldes; que Colombia ya había solicitado neutralidad a Venezuela, quien mantuvo un silencio deliberado; y, por último, es Venezuela quien decide empezar el pleito suspendiendo relaciones comerciales en la ruta Zulia-Catatumbo, tan indispensable para los comerciantes de ambos lados de la frontera (D.O., 1 de noviembre de 1901:806-807). Por medio del decreto 1287 de 1901, se hizo efectiva la ruptura total de las relaciones binacionales, hasta 1904. El gobierno venezolano siempre admitió el odio que se tenían mutuamente entre sí los "godos" y los "amarillos". Temía, además, una guerra internacional, temor que sólo podía ser aliviado en la medida que las fuerzas colombianas eran derrotadas en Venezuela o al interior de Colombia por las fueras insurgentes. En una carta que le envió Castro a su hermano Celestino, en noviembre de 1901, decía: "Ahora, sobre el Decreto de Marroquín, debo decirte que jamás se había visto Decreto más peregrino, y únicamente prueba la demencia en que está aquel Gobierno. Yo creí, cuando empecé a leer el mencionado Decreto, que iba el Señor Marroquín a declarar la guerra. De manera, pues, que no dudo en calificarlo de parto de los montes" (Boletín del Archivo Histórico de Miraflores, No.5:123) ¿Qué temían verdaderamente los estados colombiano y venezolano?, ¿qué tipo de apoyo y a cambio de qué se producían los juegos sistemáticos de apoyo y clandestinidad? 
A decir verdad, ambos bandos ofrecieron la mejor carnada al mejor postor. Pero ciertamente, el apoyo de cada país estaba supeditado al avance o triunfos de los rebeldes. Venezuela, Ecuador y Nicaragua, por ejemplo, cuando los liberales eran derrotados, asumían una posición de neutralidad e incluso incautaban armas y buques de los rebeldes, para no levantar sospechas (Durán, 1920:125; Carta de Berti a Galvis, 1901, en D.M.P., 1904:438). Todo se trataba, en el fondo, de sostener los regímenes de uno y otro lado. Muy bien lo resumió Berti en su carta a Galvis de 1901 (D.M.P., 1904:438): "no había necesidad para saber que los Gobiernos del Ecuador, Nicaragua y Venezuela no pueden contar con un solo día de paz si la revolución colombiana llegara á ser vencida". El gobierno colombiano, por tal razón, nunca se atrevió a conquistar territorios fronterizos, en primer lugar, porque no se trataba de una guerra internacional, y en segundo lugar, porque la idea era simplemente ayudar a los bandos aliados a derrocar los regímenes amenazantes para Colombia. Era suficiente ya con los descuidados territorios fronterizos propios.

En cuanto a los conservadores, es decir, los representantes oficiales del gobierno colombiano, las negociaciones de los recursos, apoyo y consecución de materiales bélicos, cuando no se limitaba a una simple censura o invocación de los principios de responsabilidad y la neutralidad, el gobierno, pues, se veía abocado a hacerlo también de una forma clandestina, como sería el caso de las dos guerras clandestinas libradas contra Ecuador y Venezuela en 1900 y 1901, comandadas por conservadores de aquellos países refugiados o exiliados en Colombia (D.M.P., 1904:209, 211-212; A.H.M, 1940); los conatos de guerra con Venezuela motivada por la guerra civil de 1876 (Rivas, 1961:474) y con Ecuador por su guerra civil de 1882 (Anales, 1914:231). Casi todos estos intentos de guerra internacional, que en el fondo era una continuación de la guerra civil por otros medios -clandestinos e internacionales- terminarían en un rotundo fracaso, por lo que el Estado colombiano asumía una posición de indiferencia pero al mismo tiempo defensor del Derecho Internacional, al declarar un absoluto desconocimiento de estos enfrentamientos (Caballero, 1939:82-87; D.M.P., 1904:208-213, 219; Tamayo, 1938:189). Una forma más sencilla de atraer recursos extranjeros para repeler las revoluciones era la adquisición de créditos o el concurso moral o real de las tropas extranjeras (Palacio, 1936:149, 152; D.M.P., 1904:439), como solía ocurrir con los norteamericanos, a quien se le sopesa una posición ambigua, en la que apoyaba a rebeldes o fuerzas del gobierno con o sin consentimiento de éste, como fue el caso de la guerra de 1885 en la Cartagena sitiada (Palacio, 1936), o en Panamá en 1903 (D.M.P., 1904).

Por último, es necesario recalcar que el papel de Colombia frente a las potencias, hasta 1902, mantuvo una confusa posición, ya que si bien adujo la protección de Estados Unidos frente a los rebeldes y a los británicos en torno al Istmo de Panamá, lo hizo a sabiendas del poder y las intenciones reales de aquél país. Más allá de asumir un equilibrio de poder trial con Estados Unidos y Gran Bretaña (cada vez más decadente este último después de 1870-75), Colombia 
reconocía la necesidad de salvaguardar la soberanía sobre el Istmo a través del apoyo moral y militar (Palacio, 1936; Borda, 1974) ante el acecho constante de Gran Bretaña, quien calificaba a Panamá de ser un Estado mal gobernado y que adolece "de tantos defectos" (Carta del Vicecónsul británico Arthur Chapman, 1883, en Anales, 283). Como si se tratara de un consulado oriental, el gobierno colombiano respondió que el de Panamá no venía al caso, y que Gran Bretaña estaba propiciando la expansión de su Imperio con el estilo consular de Oriente (I.S.R.E., Julio E. Pérez, 1884, en Anales, 1914:283).

Del lado de los combatientes también vale decir que conocían el Derecho Internacional de una manera asombrosa; la diferencia radica, como era de esperarse en el siglo XIX, en que los rebeldes supusieron en este Derecho el garante de su proceso belicista y su legitimación desde el propio Sistema Internacional. Mientras que el gobierno colombiano asumió, como era de esperarse, la posición «oficial» y la interpretación del Derecho de Gentes referente a las guerras civiles, los combatientes, por su parte, publicaron y manifestaron por todas partes que nunca habían violado los parámetros básicos de la guerra, que no recayeron en Traición a la Patria (ya que adujeron que era una guerra civil entre copartidarios internacionales y no una guerra entre naciones) y que siempre condujeron la guerra por medios civilizados -cultos, según Caballero (1939:88)- y justos (ver también D.M.P., 1904:52-55, 217-218, 219, 289). Más aún, Benjamín Herrera, en varias Circulares que aparecieron entre 1899 y 1902, sentenció que el gobierno colombiano era quien estaba llevando a cabo una guerra injusta, ilegal, y que violaba todos los parámetros del Derecho Internacional, como adversarios que "barbarizan la guerra" y efectúa represalias como "atentados de lesa humanidad" (Caballero, 1939:91-92). Es de recalcar, por ende, que para los combatientes del siglo XIX las "labores, estas obras, son un derecho indiscutible para el partido que las cumple y una facultad potestativa en toda nación que las otorgue" (Caballero, 1939:90).

Sin embargo, para el Estado, eran simplemente extranjeros perniciosos, agentes consulares y diplomáticos traidores, violadores de la neutralidad y del Derecho de Gentes. Muchos pasaron por falsos agentes diplomáticos. En tal virtud, el gobierno expidió en septiembre de 1900 un decreto para restringir el uso de pasaportes a extranjeros que se movilizaban de una localidad a otra. Todas las legaciones, curiosamente, lo aceptaron. La guerra de 1899 fue la guerra de la cancelación de exequaturs: al cónsul de Brasil, al cónsul de Colombia en Estados Unidos, al cónsul de Ecuador en Panamá, al vicecónsul de Estados Unidos en Bogotá, de todos los agentes diplomáticos de Venezuela cuando se rompen las relaciones binacionales, entre otros más (D.O., 1900, 1901). En todos los casos se adujo que la medida fue tomada porque los agentes habían apoyado a los rebeldes liberales; en todos los casos, los gobiernos extranjeros apoyaron la decisión colombiana. Por su parte, el gobierno colombiano fue fiel a la posición que asumió desde 1870-80 en torno al tratamiento de los extranjeros expropiados durante la contienda civil. Entre 1895 y 1903 aparecen reportados innumerables extranjeros perjudicados que 
hicieron reclamaciones al gobierno colombiano, y sólo en la medida que se les comprobó que fueron expropiaciones hechas por el Estado, se les retribuyeron todos sus haberes (en el D.O., 1903:710, aparecen 53 extranjeros beneficiados).

\section{LA DIPLOMACIA PRAGMÁTICA FRENTE A ESTADOS UNIDOS}

Con referencia a Estados Unidos, las relaciones internacionales de las guerras civiles estuvieron marcadas por dos aspectos críticos: 1) el tratamiento a ciudadanos y diplomáticos norteamericanos que tuvieron alguna injerencia en las guerras civiles, y, en consecuencia, una clara participación de los funcionarios norteamericanos en los asuntos internos de Colombia, que desembocaría en una controvertible violación al Derecho Internacional. 2) la cuestión Panamá, que si bien se convertiría en un asunto que marcaría todas las relaciones internacionales de Colombia durante el periodo 1885-1920, en todas sus facetas, niveles y gradaciones, en este estudio le daremos un énfasis especial a la cuestión desde la perspectiva de las guerras civiles, esto es, a la participación del gobierno norteamericano $-\mathrm{y}$ de algunos ciudadanos particulares de ese país- en torno a las guerras civiles, su apoyo e invasiones para repeler los movimientos antigobiernistas de los rebeldes y asegurar la libertad del Istmo. (En este segundo aspecto sobresale el controvertible hecho de que Estados Unidos promovía o patrocinaba clandestinamente a los rebeldes del Istmo durante la contienda de 1899, con el fin de asegurar la definitiva secesión de Panamá y tener el camino expedito para la construcción del Canal). Comencemos por el primer aspecto.

Hasta c.1900, las relaciones entre Colombia y Estados Unidos se cristalizaron de un modo más bien pragmático. Si bien el estado colombiano mantuvo una postura firme y honrada, una especie de diplomacia de caballeros, desde 1846-48 los Estados Unidos emprendieron una carrera protagónica en América, que se suspendió temporalmente por la Guerra de Secesión y la crisis de los precios entre 1873-1897; una vez superadas estas contingencias, la nación americana embistió nuevamente en lo que consideraría su zona de influencia inmediata: el Caribe insular, Centroamérica y la zona del Canal. Pero el tratamiento hacia el gobierno colombiano, hasta 1900, estuvo basado en lo que Chamberlain reseñaba claramente como el afluente del Derecho Internacional de la época:

\footnotetext{
"[...] la diplomacia se reduce hoy á 'extender el imperio del derecho y hacer más digna de aprecio la justicia pública'; 'que el Derecho de Gentes está basado en la ley moral y ella está incluido el asentimiento de los pueblos civilizados respecto á sus derechos y deberes recíprocos'; y la tercera, que 'todas las naciones gozan de iguales derechos, las viejas como las nuevas, las grandes como las pequeñas, las monarquías como las repúblicas'" (Chamberlain, 1912:6).
}

RELACIONES INTERNACIONALES DE LAS GUERRAS CIVILES, COLOMBIA, 1885-1903 
De hecho, durante las guerras civiles comprendidas en este estudio, los ciudadanos y funcionarios norteamericanos que participaron en las contiendas, fueron tratados como si se tratasen de "extranjeros perniciosos», con la misma condición de cualquier otro extranjero no perteneciente a una potencia. Más aún, de acuerdo a los archivos consultados, pudimos detectar cierta tendencia de los funcionarios colombianos hacia un nacionalismo temprano producto de la creciente influencia y poder económico de los norteamericanos radicados en Colombia. En la guerra de 1885, por ejemplo, la Legación de Estados Unidos en Bogotá, protestó por la invasión de autoridades locales de Santander a la propiedad del cónsul norteamericano Mr. Keller, en Bucaramanga, aduciendo que éste apoyaba indirectamente a los rebeldes liberales del estado. Acusó, además, al gobierno colombiano por violar el derecho público y el tratado de 1851, referente a la neutralidad en los casos de guerra civil (Archivo Diplomático y Consular, Legación de los Estados Unidos, 1882-1885, A.G.N). En este sentido,

\footnotetext{
"El espíritu de los Tratados existentes entre los Estados Unidos y Colombia es la reciprocidad de derechos y privilegios.

"Si la circunstancia de la guerra civil en uno ú otro país destruye esas garantías; porque, en tanto que los extranjeros domiciliados conserven su carácter neutral, la guerra, respecto de ellos, es como si no existiera.

"Ciertamente, toda nación al ejercer su soberanía, puede declarar la ley marcial, y en virtud de ella suspender las funciones de sus cortes legales; pero eso no suspende las funciones y las garantías de los tratados. La morada de un ciudadano de uno ú otro país en el territorio del otro, es siempre sagrada" (Memorando del Embajador de Estados Unidos, Sr. Scruggs, Agosto 15 de 1885, (Archivo Diplomático y Consular, Legación de los Estados Unidos, 1882-1885, A.G.N.).
}

El espíritu de tales convenios estipulaba que sólo se podría ingresar en las casas de diplomáticos por expresa autorización de autoridad competente reconocida. Después de una investigación se determinó que no hubo intención de violar el domicilio del Cónsul y que tampoco se estipuló una autorización expresa por parte del gobierno estatal (Legación de los Estados Unidos, Bogotá, Agosto 24 de 1885, A.G.N.). En el Memorando del Sr. Scruggs, de agosto 8 de 1885, se hace referencia a la acusación del Sr. Hallan, vicecónsul de Estados Unidos en Honda, y al ciudadano norteamericano Bain, por guardar en su casa elementos y pertrechos a hombres rebeldes; también pide revisar acusación y presunta violación de la neutralidad. El Estado del Tolima responde: "Es inexacto en jeneral lo informado [...] acerca de allanamiento de la casa del ciudadano Bain y de vejación de muebles suyos. En cuanto á que el Señor Bain haya infrinjido su neutralidad en la actual situación de guerra y en contra del gobierno, más de un motivo se tiene para afirmarlo: una mujer de muy viciosa conducta, que habitaba con el Señor Bain" era comúnmente conocida por rebelde, la refugiaba (Legación de los Estados Unidos, A.G.N.). Debe anotarse que en el caso aludido de Honda, involucrados un ciudadano 
norteamericano y un vicecónsul, mostró un claro y temprano nacionalismo conservador, por el tratamiento y humillaciones propinadas a los extranjeros.

Esta situación se reflejó durante el curso de la contienda. Se denunciaron repetidamente la violación de propiedades a norteamericanos por parte de autoridades locales. Las plantaciones de azúcar cerca de Palmira del ciudadano norteamericano James Eder por parte de las fuerzas del gobierno caucano fue un ejemplo de ello (Legación de Estados Unidos, Bogotá, Abril 8 de 1885, A.G.N.). En el Memorando del Sr. Scruggs, de agosto 15 de 1885, se acusa nuevamente a las fuerzas del Gobierno de violar la residencia de un ciudadano norteamericano, el Sr. Cander, sin autorización ni orden. El gobierno del Cauca responde que Eder "goza de garantías y sus propiedades han sido respetadas, pues no ha ejercido hostilidades contra Gobierno de la Nación y del Estado. No puede expedírseles salvo conducto á los peones de su hacienda porque todos los caucanos están obligados, conforme á la ley 315 de 1871 á prestar el servicio militar" (Telegrama del Gobernador del Estado del Cauca, Cali, 13 de Mayo de 1885, Legación de los Estados Unidos, A.G.N.).

El Consulado General de los Estados Unidos de América en Panamá, llevó el caso de la Señora Casadevall, protesta encaminada por la expropiación hecha por el jefe revolucionario Gr. Aizpuro en Panamá, quien tomó parte del Istmo en marzo de 1885. Dice que el gobierno nacional o el de Panamá deben resarcir sus haberes. El gobierno de Panamá responde en mayo que este caso se resuelve a través de lo expuesto en la Ley 60 de 1882, "Respecto de las garantías para las personas y la propiedad en tiempo de guerra": la responsabilidad recae sobre los rebeldes y el gobierno está en la obligación de hacerlos cumplir (Legación de los Estados Unidos, julio 3 de 1885, A.G.N.).

Por último, en el curso de la contienda de los Mil Días, aparecen numerosos casos de cónsules, vicecónsules y ciudadanos norteamericanos expropiados por los rebeldes, por un lado, o expulsados por el gobierno nacional, implicados en una virtual condescendencia o apoyo a los rebeldes, por otro lado (en el Diario Oficial de 1900 aparece reportado la cancelación de un exequatur a un cónsul norteamericano por promover la revolución en Bocas del Toro, D.O., 1900:509; en diciembre de 1900 aparece reportada otra cancelación a un vicecónsul americano, D.O., 1900:791; en ambos casos el gobierno norteamericano responde positivamente). Un caso bastante sonado fue el del periódico Star and Herald, radicado en Ciudad de Panamá. El gobernador de Panamá, en 1885, general Santodomingo Vila, cerró las instalaciones del periódico por supuestas relaciones clandestinas con los rebeldes liberales del Istmo. Tras la censura, vinieron diversos reclamos: el más importante de ellos, que el periódico tenía matrícula en Estados Unidos, y por tanto, debía ser juzgado según la ley de ese país. El general Santodomingo fue destituido. El gobierno colombiano se refugió en una premisa básica del derecho internacional para justificar su irresponsabilidad en caso de una 
indemnización. Adujo que si "hubiese conocido en tiempo útil el hecho ilícito, sin querer impedirlo; que teniendo el tiempo necesario para impedir los efectos del hecho de su agente, no hubiera hecho inmediatamente lo necesario para frustarlo"; que habiendo incluso destituido a su agente; que comprobando que el periódico no cumple "con los requisitos que exigen las leyes de los Estados Unidos para ser considerada la empresa como americana"; que el caso se deberá resolver de acuerdo a las leyes colombianas, "pidió que se diera, en consecuencia, por terminado el desagradable litigio, como en efecto sucedió", sin indemnización alguna (Rivas, 1961:539).

\section{El imbroglio Panamá:}

Desde 1900, el rumbo de la política internacional adquiere otra tonalidad. Esto lo entendieron bien todos los analistas, publicistas y diplomáticos colombianos de finales del siglo XIX. La historia de las guerras civiles en el Istmo de Panamá es diciente: "En todas las Repúblicas de la América del Sur se advierte hoy un vivo sentimiento de recelo y aun de manifiesto temor en presencia de la expansión que está tomando el poder de los Estados Unidos" (Memorando de Carlos Martínez Silva, 1901, en el Libro Azul, Documentos Diplomáticos sobre el Canal y la Rebelión del Istmo de Panamá, 1904: 53. En adelante Libro Azul). Carlos Martínez Silva, embajador de Colombia en Estados Unidos, comprendía bien la situación:

\footnotetext{
“Otra contingencia que pudiera también presentarse sería la de que el Gobierno de los Estados Unidos, á quien tanto se teme hoy en Colombia por sus tendencias imperialistas y absorbentes, resuelto á adquirir la vía de Panamá y á impedir que este canal se abra por los europeos, fomentara -bajo mano- las impaciencias y el descontento de Panamá, y promoviera allí un movimiento separatista, primero, y de anexión luego, á la Unión Americana" (Memorando de Carlos Martínez Silva, 1901, en el Libro Azul:47).
}

Si bien en Panamá, desde la misma Independencia, existían muchos elementos proamericanos, gérmenes de separatismo y una visión de su identidad antes bien anticolombiana, lo cierto es que una política clandestina promovida por el gobierno norteamericano para azuzar la separación definitiva de Panamá y ejercer el control absoluto del Canal, es en cierto modo acomodaticia. En el ambiente de la época se reconocía la actitud tentacular del imperialismo norteamericano, pero seguían creyendo que "la historia entera del país, y sobre todo su historia de los últimos treinta años, demuestra á toda luz que la Nación americana busca sus objetivos con franqueza, con grandeza de ánimo, con el espíritu de gran señor que quiere y puede pagar generosamente lo que necesita [...]; uncle Sam no gusta de que lo engañen en un negocio, es verdad; pero está resuelto á exhibirse delante del mundo como algo superior á un mezquino traficante de aldea" (Carta de Enrique Cortés a José Vicente Concha, 1902, en el Libro Azul:240-241). Del mismo modo se puede esclarecer esta situación con referencia al 
ánimo separatista panameño. Los panameños reconocían que estaban identificados con una visión universal de su carácter y estilo de vida, a los "intereses mercantiles, tan íntimamente ligados con los del resto del mundo, pero que "siendo del todo artificiales las relaciones del Estado de Panamá con el resto del país, él se ha hallado desde tiempo atrás unido formando una misma nacionalidad" (El Convenio de Colón, 1863:6-7).

Con todo, cabe advertir que entre 1885 y 1903 las condiciones para la separación habían ya madurado. Y tal parece que esta evolución se debió en gran parte al estado de conmociones interiores o de guerra civil permanente en Colombia y en el Istmo. Los mismos panameños detestaban tal situación:

\footnotetext{
"Jamas las guerras civiles que con frecuencia devastan el territorio granadino han tenido oríjen en el Estado de Panamá, i él ha sufrido siempre las consecuencias. Su comercio, que es su vida, ha esperimentado gran decrecencia; su pequeña industria ha caído en la nulidad; sus hijos han ido a perecer en playas lejanas i semi-estranjeras, por causas que apénas comprendian i en que no tenian ningun interés real; i en suma, el gobierno nacional, impotente para acordarle ninguna proteccion durante esas épocas tempestuosas, tenia toda la eficacia para hacerle el mal en forma de reclutamientos [...]" (El Convenio de Colón, 1863:20-21).
}

En 1901, Carlos Martínez Silva, el embajador de Colombia en Estados Unidos, advertía que "Es peligroso en estos tiempos sentar fama de bárbaros; y son precisamente los revoltosos y los opresores en las Repúblicas suramericanas los apóstoles más eficaces en favor de la conquista de nuestro suelo por las potencias que se creen guardianes de los fueros de la civilización". Seguía Martínez Silva recordando que "El supremo peligro para nuestra independencia es nuestra propia miseria, que engendra las guerras, con todo su cortejo de barbarie" (Memorando de 1901, Libro Azul, 1904:54-55). La solución para estos publicistas y diplomáticos se encaminaba por tres posibles vías: la apertura del Canal por parte de Estados Unidos -y no de Francia o Inglaterra-; la defensa de la soberanía del Istmo a cambio de la salvaguarda de la neutralidad por parte de Estados Unidos -el tratado Clayton-Bulwer de 1850 y el tratado Mallarino-Bidlack de 1846-48 y las múltiples interpretaciones del artículo 35 referente a la garantía neutralidad/soberanía; y las intervenciones norteamericanas en el Istmo en caso de guerra civil, guerra internacional y la suspensión del paso interoceánico a las mercancías y buques de naciones neutrales.

En un modo significativo, las tres propuestas estaban realmente interconectadas. Desde la ratificación del Tratado de 1846-48, el artículo 35, referente a la salvaguarda de la neutralidad del Istmo, se prestó a múltiples y descaradas interpretaciones. Pero a decir verdad, los Estados Unidos respetaron tal cual la cláusula de soberanía de Colombia sobre el Istmo, hasta 1900. Así ocurrió en 1858: “Cuando por primera vez usaron los Estados Unidos del derecho de 
tránsito por el Istmo que les garantiza el Tratado vigente, fue con el fin simplemente de llevar tropas del Oregón y California, y lo ejecutaron desembarcándolas y haciéndolas pasar al través del Istmo, sin dar aviso previo alguno á las autoridades granadinas" (José Vicente Concha, 1902, Libro Azul, 1904:262). La Legación colombiana protestó inmediatamente, motivando a interpretar el Tratado en el sentido de que se "acordó que en lo sucesivo cuando hubiesen de pasar fuerzas americanas por el territorio del Istmo, lo harían desarmadas y como grupos de simples individuos particulares" (Concha, 1902:263), reconociendo, de este modo, la neutralidad del Istmo y la soberanía de Colombia.

En la guerra civil de 1885 el estado colombiano pidió la ayuda del gobierno norteamericano para repeler la rebelión en el Istmo. La oposición al gobierno de Nuñez calificó tal hecho de vergonzoso. Con tal solicitud, sin embargo, el estado pudo probar nuevamente que tenía la potestad soberana sobre el Istmo. Además el gobierno trató de justificar sus actos: “El Presidente Nuñez estaba frente a un hecho cumplido y ante desgraciados hechos, igualmente cumplidos, en los cuales ni él mismo, ni ninguno de sus agentes, tenía la menor responsabilidad o culpa" (Palacio, 1936:148). Por tal motivo, por más "doloroso, irritante para el patriotismo [...] no quedaba otro recurso, otro remedio, que el de proveer haciendo lo posible y aun lo imposible al envío de fuerzas al Istmo para restablecer la total, absoluta soberanía de Colombia" (Palacio, 1936:148). En la guerra de 1885, sin embargo, "puede verse claramente que cuando en aquel año los Estados Unidos enviaron fuerzas a Panamá, á pesar de haber desaparecido casi por completo en ese entonces el tren de Gobierno allí, de estar indefensa la línea del ferrocarril, y de haber llegado uno de los bandos contendores hasta el extremo de reducir á prisión al Cónsul americano, nunca pretendió el gobierno americano ejecutar allí actos de autoridad y jurisdicción" (Concha, 1902:263).

La guerra de 1899 marca un rumbo diferente en la interpretación del artículo 35 del Tratado de 1846. Motivados por la construcción de un Canal exclusivamente americano, "un nuevo movimiento revolucionario en el Istmo podría determinar la inmediata ocupación del territorio por fuerzas de los Estados Unidos" (Martínez Silva, 1901, Libro Azul:47). El territorio de Panamá fue invadido por tropas norteamericanas en 1900, 1901 y 1902, que aunque se retiraron, y aunque lo hicieron con la anuencia del estado colombiano, lo cierto es que desembarcaban en Panamá "para desarmar las del soberano del territorio" (Concha, 1902, Libro Azul, 1904:263). En 1885, las tropas norteamericanas, durante trece horas y media, con doce soldados, custodiaron las propiedades de sus ciudadanos; ese mismo año, cuando se interrumpió la comunicación por el canal, desembarcaron tropas por más de cincuenta y seis días. En 1901 protegieron el tránsito durante catorce días; en 1902 durante sesenta y dos días; en 1903 lo hicieron para siempre. De este modo, durante los diez y ocho años que ocupa este estudio, las tropas norteamericanas ocuparon el Istmo durante más o menos ciento treinta y dos días, con poco más de ocho cientos hombres, en todos los casos con la anuencia del estado 
colombiano, y en pocos casos cumpliendo con la previsión del artículo 35 del Tratado de 1846. Solamente en los casos de 1901 y 1902 se puede ver claramente que se interrumpió el paso por el Istmo, se atacaron las propiedades de los norteamericanos y se violó la inmunidad de los funcionarios diplomáticos a causa de la guerra civil; pero en ningún caso hubo enfrentamientos o peligro alguno de que se obstruyera totalmente el paso por el Istmo (Chamberlain, 1912:10-11).

Los diplomáticos colombianos, sin embargo, seguían admitiendo que la guerra civil en el Departamento de Panamá era cada vez más insostenible, "y ni el gobierno local ni el nacional han podido restablecer allí el orden; y si no fuera por la intervención americana, Panamá y Colón habrían sido teatro de sangrientas escenas, y el tráfico internacional habría sido interrumpido" (Carta de Martínez Silva a Concha, 1902, Libro Azul, 1904:146). Fue a partir de entonces cuando más pragmática se hizo la diplomacia colombiana. Por un lado, era bien sabido que los rebeldes liberales eran apoyados por las fuerzas de Nicaragua: "La persistente ayuda que el Gobierno y pueblo de Nicaragua han dado á la revolución en el Istmo de Panamá, la cual, dada las circunstancias del caso [...] provenía, no de circunstancias morales, sino de una torcida política que, exhibiendo á Colombia debatiéndose en las garras de una feroz contienda civil, apartase de ella las simpatías del pueblo y Gobierno americanos" (Carta de Cortés a Concha, 1902, Libro Azul, 1904:239). Se creía incluso que era la forma como Nicaragua estaba presionando para que Estados Unidos se decidiera por una ruta alternativa por ese país. Por otro lado, la presión de la prensa, senadores y diplomáticos norteamericanos a favor de la construcción de un Canal por la vía panameña, era cada vez más apremiante. La invasión de Estados Unidos a Panamá en octubre-noviembre de 1902 fue decisiva para presionar al estado colombiano. En tal sentido, el estado colombiano comenzó a ceder en su idea de negociar la apertura del Canal otorgando buena parte de su soberanía. Razón de sobra para dedicar un acápite especial de pragmatismo en las relaciones con Estados Unidos.

Uribe Uribe, por su parte, hacía el contrapeso liberal de la oposición a tales iniciativas: "ni es que cuando para combatirnos no vacilan nuestros enemigos en sacrificar la prórroga de la concesión del Canal, la prolongación del Ferrocarril de Panamá, y aun acaso, á la hora presente, el propio Istmo, á trueque de miserias para exterminarnos" (Carta de Uribe Uribe a Juan Antonio Hernández y Teodosio Sánchez, 1901, en D.M.P., 1904:217). Por supuesto, a los diplomáticos colombianos no les quedaba más remedio que sugerir la inmediata terminación de la guerra, causante de las múltiples intervenciones norteamericanas, por un lado, y limitarse la integridad de la soberanía, por el otro. Esta era la recomendación que le hacía Ricardo Becerra (exembajador de Colombia en Estados Unidos) al entonces Canciller Concha:

“Como usted sabe, fui decididamente adverso á toda concesión que pudiera menoscabar nuestra soberanía; pero le confieso con ingenuidad que las tristes circunstancias de nuestro país han modificado 
mucho mis convicciones á este respecto. El espíritu de violencia tan bien encarnado en el nuevo liberalismo de nuestra Patria, nos coloca en la dura alternativa, ó de perder por completo esa Patria, si aceptamos la noción de que ella representa simplemente el terruño y la salvaje independencia de algunos de los que se disputan su dominación, ó de hacer un sacrificio que, salvándonos de la barbarie, nos permita, andando el tiempo, conciliar el interés de es Patria con el superior interés de la civilización [...]. Nuestro interés por la integridad de la soberanía debe limitarse, ya que no es posible otra cosa, á no comprometerla fundamentalmente y por tiempo indefinido" (Carta de Becerra a Concha, 1902, Libro Azul, 1904:143-144).

Ya como exembajador en 1902, Carlos Martínez Silva le recomendaba a Concha que "El punto de partida que no debe perderse de vista es que el Gobierno de los Estados Unidos en ningún caso emprenderá la obra del canal por Panamá si no tiene allí un control efectivo y absoluto; y por consiguiente, si ese control no puede concedérsele, es inútil y baldío adelantar cualquiera negociación (Carta de Martínez a Concha, 1902, Libro Azul, 1904:145. La cursiva en el original). La cesión de soberanía a los Estados Unidos para el control del Canal y las seis millas que lo bordean en el tramo de la faja interoceánica, no obedecía únicamente a una lógica puramente política. Lo era también una cuestión de barbarie o civilización. Esencialmente, la percepción de los Estados Unidos y Europa hacia algunos países de América Latina -extendido a Asia y África-, a la luz de la moral y la ética cristiana más radical, era una percepción denigrativa, una especie de «insolencia» y superioridad hiriente que jugaba con los términos de un darwinismo social y una fuerte dosis de higienización racial (una recopilación del pensamiento de la época en Martínez Silva, Libro Azul, 1904:38-57). En el interior del país, este debate apareció bajo la forma de un santanderismo degenerado, que propició Miguel Antonio Caro en la tribuna y la prensa. Este santanderismo, en palabras de los más acendrados detractores del legado del general Santander, consistía en tachar a los liberales rebeldes de propiciar en la nación colombiana un carácter anticatólico -masón- y legalista.

Fuera del país era reconocido como una simple y llana actitud rabulera y semibárbara. Bien lo reseña Martínez Silva en su carta a Concha (1902, Libro Azul, 1904:146): “Aquí [en Estados Unidos] se nos juzga á todos los suramericanos como muy dados al enredo, á la procastinación, á la sensiblería, á los expedientes tinterillescos, al formulismo; no se cree en nuestras leyes escritas, que á menudo son violadas, ni en nuestros procedimientos judiciales y administrativos, ni en nuestra honradez pública, ni en nuestra seriedad, ni en nuestra eficiencia y capacidad para las funciones de gobierno". Para los publicistas colombianos quedaban sólo dos caminos: el primero, preferir el "concepto abstracto de soberanía" (Martínez Silva a Concha, 1902, Libro Azul, 1904:147), en que se cedía todo el derecho de policía y la administración judicial del Istmo a los Estados Unidos, pero sólo en la medida en que se reconociera la soberanía 
territorial de Colombia sobre el Departamento de Panamá. El segundo camino consistía en abordar una especie de Congreso bolivariano, esto es, un Congreso Latino-Americano, capaz de generar un cuerpo de resistencia a los embates imperialistas de Estados Unidos o Europa. Todo indica que ya nadie creía en la supuesta doctrina de No Intervención -Doctrina Monroede la potencia americana, y esto se debió en parte a la empresa expansionista de los Estados Unidos, triunfante, en el Caribe insular, que, por un lado, desplazó el último reducto de la monarquía española en América, y, por el otro, consolidó, con la independencia de Cuba y Puerto Rico, la supremacía en este continente de la República del Norte.

Promotores de tal Congreso Latino-Americano, refulgurante por su discurso idealista, habían sido conservadores moderados del corte de los senadores Carlos Calderón y Jorge Holguín, transcurridos los años de 1898 y 1899 (Borda, 1898:30-31). Francisco de Paula Borda se había caracterizado por ser uno de los más recalcitrantes detractores conservadores al régimen regeneracionista de Nuñez y Caro; por tanto, era un detractor de la diplomacia pragmática frente a los Estados Unidos. Era un idealista empírico, si se nos permite el término. En su carta a los senadores Calderón y Holguín, los felicitaba por la iniciativa de un Congreso LatinoAmericano, y, además, reconocía el impulso que arrastraba consigo la potencia americana. Como consecuencia del inevitable triunfo de Estados Unidos sobre España, calculado desde 1898, hizo semejante análisis:

“[...] el contrapeso inesperado de una nueva y gran potencia marítima en la gestión de los asuntos europeos y en lo que se ha llamado equilibrio de las naciones en aquel Continente; la súbita y obligada modificación en la actitud de cada uno de los gobiernos de Europa en lo que con América se relaciona; la intervención de los americanos del Norte en la vieja y complicada cuestión de Oriente, dislocándola, como para iniciar de una vez la lucha de los elementos mogólicos contra la civilización occidental, de la cual no son aliados en el lógico desarrollo de la historia; el desequilibrio, en fin, del poder y de los intereses marítimos del mundo, no estimulados hoy por grandeza alguna ó promesa de grandeza en las colonias europeas en el Atlántico, dan á los Estados Unidos influencia por ahora incontrastable y por su naturaleza absorbente en el hemisferio occidental é introducen un cambio profundo en el curso histórico de los acontecimientos humanos, mirados en su aspecto internacional" (Borda, 1898:32-33. Las cursivas en el original).

Para Borda, los aspectos que dislocaban la integración latinoamericana ya habían sido superados por los libertadores, que borraron con sus espadas "Ios decretos del Rey de España" y abrieron caminos increíbles en su lucha común contra el colonialismo (Borda, 1898:37). En el meollo del asunto no podía dejar de faltar el imbroglio Panamá. Debido a que la Confederación Latino-Americana se constituiría como una compacta y homogénea, "podría contar hoy mismo 
con la influencia moral y política de diez y ocho naciones que á su vez contarían cientos de millones de pesos de rentas anuales; con una escuadra fácil de formar ó completar de 70 ú 80 acorazados; con puertos que podrían fortificarse fácilmente, ó ponerse en simple estado de defensa, unidos al resto del mundo por cables eléctricos y en relaciones constantes con Europa, Asia y los Estados Unidos; con industrias propias y vasto comercio en creciente desarrollo; con el Canal de Panamá y todas las vías intermarinas bajo su dominio exclusivo" (Borda, 1898:34-35). Borda concluye su estudio formulando una especie de derecho internacional latinoamericano, que, en todo caso, no es una fuente novedosa que se separa del derecho internacional general: arbitraje, integridad territorial, garantía del Istmo de Panamá y de las vías interoceánicas, navegación de los ríos y de los extranjeros en América (Borda, 1898:4577). El Congreso colombiano aprobó tal iniciativa, y en febrero de 1901 se reunió el Congreso en Montevideo (D.O., 1901:97).

En el interim, sin embargo, semejante Congreso Latino-Americano chocaría con la realidad de la escena internacional. La inminencia de la separación de Panamá, es decir, "del peligro y la imposibilidad para Colombia de mantener su integridad", se hicieron más palpables "por las peripecias de la guerra civil en el Istmo" (Carta de Cortés a Concha, 1902, Libro Azul, 1904:242); por otra parte, algunos estados latinoamericanos, como Chile, Argentina, Nicaragua y Costa Rica, tenían otro tipo de intereses marcados en la zona del Istmo, como el tránsito libre de sus mercancías, la neutralidad a secas o la segunda vía alternativa de un Canal por el Lago de Nicaragua; además, en los casos de Costa Rica y Nicaragua, quedaba un delicado asunto de fronteras por resolver; en los demás casos, como los de Venezuela, Ecuador, Brasil y Perú, los asuntos internacionales con Colombia atravesaban por una fuerte disputa fronteriza, en las que se habían colonizado vastos territorios colombianos a punta de machete y revólver (una fuerte crítica a la debilidad del Estado colombiano con respecto a Perú y Brasil, en Escobar, 1911). Quizás la única excepción era México, quien siempre se mostró favorable a diversas iniciativas antiimperialistas propugnadas desde Colombia, naturalmente por su irresoluto destino de contar con una frontera tentacular con los Estados Unidos (véase Randall, 1992).

Todo desembocaría en la separación de Panamá en 1903. La construcción del Canal estaría en manos exclusivas de Estados Unidos. Y ni la diplomacia pragmática frente a Estados Unidos, ni la idealista Confederación Latino-Americana salvaron a Colombia de lo que los nacionalistas de la época calificaron de la peor humillación recibida en la historia del país. En las memorias de los publicistas, diplomáticos y nacionalistas recién salidos del cascarón, un siglo plagado de guerras civiles, además de la posición imperialista norteamericana, tenían que pasar al olvido y proyectar una nueva nación, conciliada, regenerada, demoliberal, secular y capitalista. 


\section{RELACIONES INTERNACIONALES DE LAS GUERRAS CIVILES (marco conclusivo):}

La política exterior colombiana durante las guerras civiles fue sensiblemente activa. Contrario a lo que comúnmente se cree, las relaciones internacionales de Colombia merecieron un lugar prioritario en los anaqueles de los hombres políticos e intelectuales de los años finales del siglo XIX. En esta Investigación tratamos de demostrar que la historia colombiana también tiene un fuerte componente internacional, que, según la perspectiva de las Relaciones Internacionales, nos induce a pensar que subyacen elementos en el sistema, exógenos o endógenos a él, que determinan su existencia, desarrollo y dinamismo. Tales elementos suelen ser perdurables en el tiempo, y en la medida que se modifican (caos-resquebrajamientotransición), también permanecen pululando algunos de los elementos "viejos" (regularidades) que o bien se transforman (pero mantienen su esencia) o bien perduran (Arrighi y Silver, et. al., 2001:29; Wallerstein, 2004:412 y ss.; Abu Lughod, 1989:368-369).

De acuerdo a esto, pudimos enmarcar las tres guerras civiles indicadas en este estudio (1885, $1895,1899)$ en el sistema internacional imperante, en un sentido: las guerras civiles son determinadas -o son condicionadas, más bien-, por la estructura general del sistema, que en el periodo de estudio aquí comprendido, estaba fuertemente cargado por el ímpetu de los nacionalismos, las revoluciones sociales y las luchas de reivindicación de los radicales liberales y socialistas en todo el mundo occidental. A manera de balance proponemos el siguiente marco de aproximación (ver también Cuadro No. 1):

1. Apoyo logístico de diversos Estados simpatizantes con los rebeldes combatientes, y, a la inversa, el apoyo logístico de rebeldes combatientes a los Estados que los apoyan, a favor del Estado colombiano, que se encuentran en una situación semejante. Los combatientes por lo regular sólo pueden adquirir pertrechos, armas, municiones, facilidad de desplazamiento, recursos financieros, etc., en la medida en que existan relaciones que trasciendan las fronteras y puedan perpetuar relaciones con personajes de la alta esfera política de otros Estados. Sólo estas guerras se ven encauzadas mientras cuentan con el apoyo de otros Estados, movimientos u hombres con la misma convicción y espíritu revolucionario. En términos generales, los rebeldes liberales que combatieron al estado conservador colombiano, admitían que para que la revolución marchara por buen camino, se requería del apoyo logístico de los estados vecinos, tales como Nicaragua, Venezuela, Ecuador y El Salvador (D.M.P., 1904:159, 185-186, 193, 205-207; Durán, 1920:77, 79, 83, 129-130), o del apoyo moral o diplomático de las grandes potencias (Palacio, 1936:149, 152). Las negociaciones en torno a la consecución de recursos, apoyo, guarniciones, bases, libertad de movilidad en el exterior, entre otros factores, se hacían por medio de lo que muchos de los combatientes llamaban «correrías por el exterior»(Caballero, 1939:70, 74; Durán, 1920:79), casi siempre asumidas bajo 
los parámetros de una diplomacia partidista o extraoficial (D.M.P., 1904:XIII; Salazar, 1992:248; ver más adelante sobre los parámetros de la paradiplomacia).

2. Dicho esto, es natural que el Estado afectado por la rebelión deba tomar una posición frente a los otros Estados que apoyan directa o indirectamente a los rebeldes. La internacionalidad de los hechos se ve reflejada de esta manera por una parte y una contraparte, que traslucen sus relaciones por medio de los canjes de notas de Cancillerías, aplicación de Tratados Internacionales referentes al caso (uso del derecho de gentes, indemnizaciones, expropiaciones), rupturas de relaciones diplomáticas, antecedida por situaciones conflictivas relativas a las cancelaciones de exequatur, arreglos diplomáticos, discusión de cuestiones fronterizas, entre otros (Informe del Secretario de Relaciones Exteriores, Vicente Restrepo, 1885, en Anales, IV, 1914:391-392; D.O., 1900:225, 469470, 474, 509, 517; D.O., 1901:805-808).

3. Paradiplomacia y paradiplomáticos. En esta investigación se pudo establecer que los combatientes y el gobierno llevaron a cabo negociaciones secretas o entablaron relaciones clandestinas con otros Estados y muchos extranjeros dentro y fuera del país. La propuesta más importante de este trabajo está relacionada con las categorías de análisis que recubren a los actores de la contienda civil, de acuerdo a los parámetros antes citados: la paradiplomacia y el paradiplomático, como el escenario y los actores políticos que se mueven en el mundo de las altas esferas políticas, los movimientos literarios, culturales y periodísticos más importantes de la región y el mundo, y que los hace capaces de sentirse bajo los parámetros de la legalidad y la razón. El mismo Uribe Uribe (D.M.P., 1904:193) habló de la "Comisión Diplomática" de la Causa liberal. Tal Comisión se encargaba de nombrar "Agentes de la Revolución" en Centroamérica, Ecuador y Venezuela (Durán, 1920:123); también de encauzar los recursos, abrir nuevos contactos, reafirmar los existentes, generar vías de comunicación y labores de espionaje (carta de Berti a Galvis, septiembre de 1901, en D.M.P., 1904:438). Buena parte de estos agentes paradiplomáticos eran intelectuales-políticos, pero no necesariamente ricos o parte de familias ilustres, como fue el caso de Belisario Porras o Modesto Garcés, agentes revolucionarios en Centroamérica (Salazar, 1992; Caballero, 1939). Por último, los términos no inducen a la lectura dada por Uribe Vargas, en torno a la Diplomacia Secreta, como vimos, por no ubicar el contexto de estas necesidades alrededor de las fuerzas que motivaron al gobierno y a los rebeldes a internacionalizar el conflicto.

Por tal razón, subrayamos que la política exterior colombiana aplicada a las guerras civiles era ambiguamente «activa». El Estado colombiano tuvo que ceder a los intereses de las potencias, los rebeldes y la posición «dura» de los Estados vecinos en contra de 
su voluntad, pero adaptada a una especie de "diplomacia de caballeros», que hasta 1900 estaba basada más en los elementos de la cordialidad y los ideales de una civilización amparada en el Derecho Internacional. Si bien los gobernantes del país tuvieron una postura firme y coherente alrededor de su política externa, el estado colombiano asumió una posición de Estado soberano con respecto a los países vecinos, y de éstos respecto del Estado y los combatientes; a los preceptos del Derecho Internacional invocados por las partes en conflicto, como la neutralidad, los principios de responsabilidad e irresponsabilidad de los Estados, el tratamiento a extranjeros y diplomáticos involucrados en el conflicto, los Congresos Internacionales y su referencia a las conmociones interiores, el expansionismo de las potencias y otros factores más.

Pero a partir de la década de 1890, la política exterior colombiana fue visiblemente permeada por la aparición en escena de la potencia americana, cada vez más acuciante; esto desplaza la «diplomacia de caballeros» hacia una "diplomacia pragmática» que pretendía hacer frente al imperialismo norteamericano; en ambos tipos de «diplomacia», sin embargo, hubo un fuerte apego a los pactos secretos, a las guerras clandestinas y a la preservación de la soberanía por medios más bien oscuros. No indica esto necesariamente que tal política haya sido «efectiva», como vimos. El Estado colombiano, ciertamente, tuvo el conocimiento pleno de todos los caracteres de la política internacional, y aún la voluntad plena de enmarcar una política exterior autónoma. Aún en los casos en que lo logró, tal efectividad fue sustancialmente limitada, pero pragmática y realista. Esto es, adecuada a los parámetros de las fuerzas profundas imperantes en el contexto internacional, los movimientos intelectuales, los nacionalismos y las crisis sociales que transformaron definitivamente las sociedades en el siglo XX.

\section{BIBLIOGRAFIA}

Fuentes relativas a las Guerras Civiles y las Relaciones Internacionales:

Anales Diplomáticos y Consulares de Colombia, t. I, compilación de Antonio José Uribe, Imprenta Nacional, Bogotá, 1900.

Anales Diplomáticos y Consulares de Colombia, t. II, compilación de Antonio José Uribe, Imprenta Nacional, Bogotá, 1901.

Anales Diplomáticos y Consulares de Colombia, t. IV, compilación de Antonio José Uribe, Imprenta Nacional, Bogotá, 1914.

Andrade, Manuel de Jesús, "Andanzas de un colombiano", Ambato, Imprenta del Colegio Bolívar, 1935.

Arango, Sebastián Moreno, "Historia y Diplomacia de los EE.UU. de Colombia", Bogotá, 1940, s.e.

Archivo General de la Nación, Fondo Ministerio de Relaciones Exteriores

RELACIONES INTERNACIONALES DE LAS GUERRAS CIVILES, COLOMBIA, 1885-1903 
1. FONDO MINISTERIO DE RELACIONES EXTERIORES, LIBRO No. 116, 1898-1901, "Revoluciones del Ecuador y de Colombia".

Carta del Ministro de Relaciones Exteriores de Colombia al de Ecuador, Bogotá, 23 de marzo de 1898.

Carta del Ministro de Relaciones Exteriores de Colombia al de Ecuador, Bogotá, 31 de marzo de 1898

TELEGRAMAS Y CABLEGRAMAS:

Panamá, 17 de marzo de 1900, Ministro de Relaciones y Guerra, Bogotá

Quito, 24 de junio de 1900, M. Relaciones Exteriores, Bogotá.

Buenaventura, 4 de julio de 1900, Ministro Relaciones, Gobernador Buga

Buenaventura, 30 de julio de 1900

Panamá, 31 de agosto de 1900, Buenaventura, 4 de septiembre

Quito 17, Bva. 17 de febrero de 1900, Ministro Relaciones, Bogotá

Buenaventura., 19 de octubre de 1900, Ministro de Relaciones

Telegrama de Quito al Ministro de Colombia, enero de 1900

\section{ARCHIVO DIPLOMÁTICO Y CONSULAR, LEGACIÓN DE LOS ESTADOS UNIDOS, 1882-1885}

Legación de Estados Unidos, Bogotá, Abril 8 de 1885

Memorando del Señor Scruggs (Embajador), Abril de 1885

Memorando del Sr. Scruggs, Agosto 8 de 1885

Memorando del Sr. Scruggs, Agosto 15 de 1885

Consulado General de los Estados Unidos de América, Panamá, Julio 3 de 1885

\section{ARCHIVO DIPLOMÁTICO Y CONSULAR}

Organismos Internacionales, 1891-1904

Gabinete del Ministerio, 1898-1909

Sección Reclamaciones, 1876-1903

Legaciones Diplomáticas y Consulares. Correspondencia

Boletín del Archivo Histórico de Miraflores.

Borda, Francisco de Paula, "Conversaciones con mis hijos", t. III, Bogotá, Biblioteca Popular, 1974.

Caballero, Lucas, "Memorias de la Guerra de los Mil Días", reimpresión del Instituto Colombiano de Cultura, Bogotá, 1939.

Chamberlain, L., “Una página de deshonra nacional”, 1912. 
"Cuestiones Colombianas. La cuestión Cerruti. La sentencia Cleveland. Sus consecuencias necesarias. ¿Hubo alta traición?", Lausana, Imprenta Jorge Bridel, 1899.

Decretos Legislativos expedidos durante la guerra de 1899 á 1902, compilación de Manuel José Guzmán, Imprenta del Vapor, Bogotá, 1902.

Diario Oficial, 1884

Diario Oficial, 1885

Diario Oficial, 1886

Diario Oficial, 1895

Diario Oficial, 1886

Diario Oficial, 1899

Diario Oficial, 1900

Diario Oficial, 1901

Diario Oficial, 1902

Diario Oficial, 1903

Documentos Militares y Políticos. Relativos á las Campañas del General Rafael Uribe Uribe, Imprenta del Vapor, Bogotá, 1904.

Durán, Justo, “La Revolución del 99", Talleres Tipográficos de El Día, Cúcuta, 1920.

"El Convenio de Colón o sea los intereses políticos del Estado de Panamá como miembro de la Unión Granadina", Cartajena, Imprenta de Federico Nuñez, 1863.

Escobar, Felipe S., "Viaje alrededor de un mapa. Inmenso desastre de la Diplomacia sin cañones. 500,000 kilómetros cuadrados de territorios colombianos segregados, invadidos, usurpados, cedidos, ofrecidos...", Bogotá, Imprenta El Liberal, 1911.

Ensayos históricos y literarios de Uribe Uribe, Antología No. III, Compilación y Prólogo de Otto Morales Benítez, Plaza \& Janes Editores, 1996.

"Epistolario de Rufino José Cuervo y Miguel Antonio Caro con Antonio Gómez Restrepo", Edición de Mario Germán Romero, Bogotá, Instituto Caro y Cuervo, 1973.

Índice de las leyes colombianas sobre asuntos del ramo de Relaciones Exteriores, 1821-1927, Imprenta Nacional, Bogotá, 1928.

Informe que el Ministro de Relaciones Exteriores presenta al Congreso de 1904", Imprenta Nacional, Bogotá, 1904.

Leyes colombianas expedidas por el Congreso en sus sesiones extraordinarias de 1903, Edición Oficial, Imprenta Nacional, Bogotá, 1918.

Loor, Wilfrido, "Eloy Alfaro. 1885-1901", t. II, Quito, Editora Moderna, 1947. 
Ministerio de Relaciones Exteriores, "Libro Azul. Documentos diplomáticos sobre el Canal y la rebelión del Istmo de Panamá", Imprenta Nacional, Bogotá, 1904.

Palacio, Julio, "La Guerra del 85", Librería Colombiana Camacho Roldán, Bogotá, 1936.

Pareja Díez-Canseco, Alfredo, "La hoguera bárbara (vida de Eloy Alfaro)", México, Compañía General Editora, 1944.

Ponce Gutiérrez, Ignacio, "Reminiscencias de vida diplomática, 1879 a 1923", The Whitefriars Press, London, 1926.

República de Colombia, “Congreso Latino-Americano. Carta de F. de P. Borda a Calderón y Holguín, 1898", Bogotá, Imprenta Nacional, 1899.

Rodríguez, José Santos, "Eloy Alfaro. Su personalidad multifacética y la Revolución Liberal", Litografía e Imprenta de la Universidad de Guayaquil, 1995.

Salazar, Víctor Manuel, "Memorias de la Guerra", reimpresión de la Imprenta Departamental de Caldas, 1992.

Tamayo, Joaquín, “La Revolución de 1899”, Editorial Cromos, Bogotá, 1938.

Textos de consulta:

Abu-Lughod, Jeanet, "Before European hegemony. The World System A.D. 1250-1350", Oxford University Press, 1989.

Arrighi, Giovanni y Beverly Silver, et. al., "Caos y orden en el sistema-mundo moderno", Akal, Madrid, 2001.

Caicedo Castilla, José, "Historia Diplomática", t. I, en Historia Extensa de Colombia, vol. XVII, Ediciones Lerner, Bogotá, 1974.

Carrera Damas, Germán, "El Culto a Bolívar", Editorial Universidad Nacional de Colombia, Bogotá, 1987.

Chamberlain, L., "Una página de deshonra nacional”, 1912.

Deutsch, Karl, "El análisis de las Relaciones Internacionales", Editorial Paidós, Buenos Aires, 1968.

Fuenmayor, Juan Bautista, “Historia de la Venezuela Política Contemporánea, 1899-1969", t. I, Caracas, 1984, s.e.

Hilton, Sylvia, "América en el sistema internacional, 1783-1895, en Pereira, et.al., "Historia de las Relaciones Internacionales Contemporáneas", Ariel, Madrid, 2001.

Hobsbawm, Eric, “La era de la Revolución, 1789-1848”, Crítica, Grijalbo Mondadori, Barcelona, 1997. 
“Naciones y nacionalismo desde 1780", Crítica-Grijalbo, Barcelona, $1997 \mathrm{~b}$.

Jaramillo, Carlos Eduardo, "Los guerrilleros del novecientos", Cerec, Bogotá, 1991.

Lafeber, Walter, "The American Search for Opportunity, 1865-1913", vol. II, The Cambridge History of American Foreign Relations, Cambridge Universtiy Press, 1995.

Moreno Arango, Sebastián, "Historia y Diplomacia de los EE.UU. de Colombia", Bogotá, 1940, s.e.

Pitt, Thomas Allen, "Eloy Alfaro and Ecuador's Andean Diplomacy, 1885-1911", University of Virginia, 1976.

Randall, Stephen, "Aliados y Distantes", Tercer Mundo Editores, Universidad de los Andes, Bogotá, 1992.

Renouvin, Pierre, "Historia de las Relaciones Internacionales", t. II, V. I, Editorial Aguilar, Madrid, 1964.

"Historia de las Relaciones Internacionales", t. I, Introducción General, Editorial Aguilar, Madrid, 1960.

Rivas, Raimundo, "Historia Diplomática de Colombia, 1810-1934”, Imprenta Nacional, Bogotá, 1961.

Urrutia, Francisco José, "Le Continent American et le Droit Internacional", Rousseau \& Cie., Editeurs, París, 1928.

Vásquez Carrizosa, Alfredo, "Relatos de historia diplomática de Colombia. La Gran Colombia", t. I, Ministerio de Relaciones Exteriores, Universidad Javeriana, Bogotá, 1996.

"Relatos de historia diplomática de Colombia. Los límites de Colombia y la diferencia con Estados Unidos sobre Panamá", t. II, Ministerio de Relaciones Exteriores, Universidad Javeriana, Bogotá, 1996.

"Relatos de historia diplomática de Colombia. Siglo XX. Literatura y Política", t. I, Ministerio de Relaciones Exteriores, Universidad Javeriana, Bogotá, 2000.

Wallerstein, Immanuel, "Capitalismo histórico y movimientos antisistémicos. Un análisis de sistemasmundo", Akal, Madrid, 2004.

Yepes, J.M., “Del Congreso de Panamá a la Conferencia de Caracas, 1826-1954. El genio de Bolívar a través de la Historia de las Relaciones Internacionales", Caracas, 1955, s.e. 